\title{
TOP-DOWN VERSUS BOTTOM-UP MACROECONOMICS
}

\author{
Paul De Grauwe \\ University of Leuven
}

\begin{abstract}
:
I distinguish two types of macroeconomic models. The first type are top-down models in which some or all agents are capable of understanding the whole picture and use this superior information to determine their optimal plans. The second type are bottom-up models in which all agents experience cognitive limitations. As a result, these agents are only capable of understanding and using small bits of information. These are models in which agents use simple rules of behavior. These models are not devoid of rationality. Agents in these models behave rationally in that they are willing to learn from their mistakes.

These two types of models produce a radically different macroeconomic dynamics. I analyze these differences.
\end{abstract}

JEL codes : E10, E32, D83

Keywords : DSGE-model, imperfect information, heuristics, animal spirits

October 2009

Paper presented at the CESifo Concerence "What's wrong with modern macroeconomics?", Munich, 6-7 November 2009. I am grateful to Yunus Aksoy, Tony Atkinson, Stephan Fahr, Daniel Gros, Richard Harrison, Romain Houssa, Pablo Rovira Kaltwasser, Christian Keuschnigg, Alan Kirman, Giovanni Lombardo, Lars Ljungqvist, Patrick Minford, John Muellbauer, Ilbas Pelin, Frank Smets, Leopold von Thadden, David Vines, and Tony Yates for their comments and suggestions. 


\section{Introduction}

One of the surprising developments in macroeconomics is the systematic incorporation of the paradigm of the utility maximizing forward looking and fully informed agent into macroeconomic models. This development started with the rational expectations revolution of the 1970s, which taught us that macroeconomic models can only be accepted if agents' expectations are consistent with the underlying model structure. The real business cycle theory (RBC) introduced the idea that macroeconomic models should be "micro-founded", i.e. should be based on dynamic utility maximization. While RBC models had no place for price rigidities and other inertia, the New Keynesian School systematically introduced rigidities of all kinds into similar micro-founded models. These developments occurred in the ivory towers of academia for several decades until in recent years these models were implemented empirically in such a way that they have now become tools of analysis in the boardrooms of central banks. The most successful implementation of these developments are to be found in the Dynamic Stochastic General Equilibrium models (DSGE-models) that are increasingly used in central banks for policy analysis (see Smets and Wouters(2003), Christiano, et al.(2007), Smets and Wouters(2007), Adjemian, et al. (2007)).

These developments are surprising. While macroeconomic theory enthusiastically embraced the view that agents fully understand the structure of the underlying models in which they operate, other sciences like psychology and neurology increasingly uncovered the cognitive limitations of individuals (see e.g. Damasio(2003), Kahneman (2002), Camerer et al. (2005), Kahneman and Thaler (2006) and Della Vigna(2007)). We learn from these sciences that agents only understand small bits and pieces of the world in which they live, and instead of maximizing continuously taking all available information into account, agents use simple rules (heuristics) in guiding their behaviour and their forecasts about the future (see Gabaix, Laibson, Moloche, and Weinberg, 2006). The recent financial crisis seems to support the view that agents have limited understanding of the big picture. If they had understood the full complexity of the financial system they would have understood the lethal riskiness of the assets they massively took in their portfolios.

In order to understand the nature of different macroeconomic models it is useful to make a distinction between top-down and bottom-up systems. In its most general 
definition a top-down system is one in which one or more agents fully understand the system. These agents are capable of representing the whole system in a blueprint that they can store in their mind. Depending on their position in the system they can use this blueprint to take over the command, or they can use it to optimize their own private welfare. These are systems in which there is a one to one mapping of the information embedded in the system and the information contained in the brain of one (or more) individuals. An example of such a top-down system is a building that can be represented by a blueprint and is fully understood by the architect.

Bottom-up systems are very different in nature. These are systems in which no individual understands the whole picture. Each individual understands only a very small part of the whole. These systems function as a result of the application of simple rules by the individuals populating the system. Most living systems follow this bottom-up logic (see the beautiful description of the growth of the embryo by Dawkins(2009)). The market system is also a bottom-up system. The best description made of this bottom-up system is still the one made by Hayek(1945). Hayek argued that no individual exists who is capable of understanding the full complexity of a market system. Instead individuals only understand small bits of the total information. The main function of markets consists in aggregating this diverse information. If there were individuals capable of understanding the whole picture, we would not need markets. This was in fact Hayek's criticism of the "socialist" economists who took the view that the central planner understood the whole picture, and would therefore be able to compute the whole set of optimal prices, making the market system superfluous. (For further insightful analysis see Leijonhufvud(1993)).

My contention is that the rational expectations models are the intellectual heirs of these central planning models. Not in the sense that individuals in these rational expectations models aim at planning the whole, but in the sense that, as the central planner, they understand the whole picture. These individuals use this superior information to obtain the "optimum optimorum" for their own private welfare. In this sense they are top-down models.

In this paper I will contrast the rational expectations top-down model with a bottomup macroeconomic model. This will be a model in which agents have cognitive limitations and do not understand the whole picture (the underlying model). Instead they only understand small bits and pieces of the whole model and use simple rules to 
guide their behavior. I will introduce rationality in the model through a selection mechanism in which agents evaluate the performance of the rule they are following and decide to switch or to stick to the rule depending on how well the rule performs relative to other rules.

The modeling approach presented in this paper is not the only possible one to model agents' behaviour under imperfect information. In fact, a large literature has emerged attempting to introduce imperfect information into macroeconomic models. These attempts have been based mainly on the statistical learning approach pioneered by Sargent(1993) and Evans and Honkapohja(2001). This literature leads to important new insights (see e.g. Gaspar and Smets(2006), Orphanides and Williams(2004), Milani(2007a)). However, I feel that this approach still loads individual agents with too many cognitive skills that they probably do not posses in the real world ${ }^{1}$. In a way it can be argued that the statistical learning models are also top-down models, in which agents' ambition is to learn the secrets of the whole picture, which in these models they typically achieve asymptotically (in heaven?).

The purpose of this paper is to contrast the dynamics of the top-down and the bottomup models, and to draw some policy conclusions. The paper is very much inspired by the new literature on "agent-based macroeconomic models" (see Howitt(2008), Tesfatsion(2006), LeBaron and Tesfatsion(2008) among others). Section 2 presents the bottom-up model, which will be called "behavioural model". The next three sections then discuss the different implications the behavioural model has when contrasted with the rational expectations model. The paper is concluded with a discussion of some methodological issues.

\footnotetext{
${ }^{1}$ See the fascinating book of Gigerenzer and Todd(1999) on the use of simple heuristics as compared to statistical (regression) learning.
} 


\section{A behavioural macroeconomic model}

In this section the modeling strategy is described. This is done by presenting a standard aggregate-demand-aggregate supply model augmented with a Taylor rule. The novel feature of the model is that agents use simple rules, heuristics, to forecast the future. These rules are subjected to an adaptive learning mechanism, i.e., agents endogenously select the forecasting rules that have delivered the highest performance ("fitness") in the past. This selection mechanism acts as a disciplining device on the kind of rules that are acceptable. Since agents use different heuristics one obtains heterogeneity. This, as will be shown, creates endogenous business cycles.

This behavioural model is contrasted with a similar model that incorporates rational expectations, and that is interpreted as a stylized version of DSGE-models. This comparison will make it possible to focus on some crucial differences in the transmission of shocks, in particular of monetary policy shocks.

\subsection{The model}

The model consists of an aggregate demand equation, an aggregate supply equation and a Taylor rule.

The aggregate demand equation is specified in the standard way, i.e.

$$
y_{t}=a_{1} \widetilde{E}_{t} y_{t+1}+\left(1-a_{1}\right) y_{t-1}+a_{2}\left(r_{t}-\widetilde{E}_{t} \pi_{t+1}\right)+\varepsilon_{t}
$$

where $y_{t}$ is the output gap in period $\mathrm{t}, r_{t}$ is the nominal interest rate, $\pi_{t}$ is the rate of inflation, and $\varepsilon_{t}$ is a white noise disturbance term. $\widetilde{E}_{t}$ is the expectations operator where the tilde above $E$ refers to expectations that are not formed rationally. This process will be specified subsequently. I follow the procedure introduced in DSGEmodels of adding a lagged output in the demand equation. This is usually justified by invoking habit formation. I keep this assumption here as I want to compare the behavioural model with the DSGE-rational expectations model. However, I will show in section 4 that I do not really need this inertia-building device to generate inertia in the endogenous variables. 
The aggregate supply equation can be derived from profit maximization of individual producers. As in DSGE-models a Calvo pricing rule and some indexation rule used in adjusting prices is assumed. This leads to a lagged inflation variable in the equation ${ }^{2}$. The supply curve can also be interpreted as a New Keynesian Philips curve:

$$
\pi_{t}=b_{1} \widetilde{E}_{t} \pi_{t+1}+\left(1-b_{1}\right) \pi_{t-1}+b_{2} y_{t}+\eta_{t}
$$

Finally the Taylor rule describes the behaviour of the central bank

$$
r_{t}=c_{1}\left(\pi_{t}-\pi^{*}\right)+c_{2} y_{t}+c_{3} r_{t-1}+u_{t}
$$

where $\pi^{*}$ is the inflation target which for the sake of convenience will be set equal to 0 . Note that, as is commonly done, the central bank is assumed to smooth the interest rate. This smoothing behaviour is represented by the lagged interest rate in equation (3). Ideally, the Taylor rule should be formulated using a forward looking inflation variable, i.e. central banks set the interest rate on the basis of their forecasts about the rate of inflation. This was not done here in order to maintain simplicity in the model.

\section{Introducing heuristics in forecasting output}

Agents are assumed to use simple rules (heuristics) to forecast the future output and inflation. The way I proceed is as follows. I start with a very simple forecasting heuristics and apply it to the forecasting rules of future output. I assume two types of forecasting rules. A first rule can be called a "fundamentalist" one. Agents estimate the steady state value of the output gap (which is normalized at 0 ) and use this to forecast the future output gap. (In a later extension, it will be assumed that agents do not know the steady state output gap with certainty and only have biased estimates of it). A second forecasting rule is an "extrapolative" one. This is a rule that does not presuppose that agents know the steady state output gap. They are agnostic about it. Instead, they extrapolate the previous observed output gap into the future.

The two rules are specified as follows

The fundamentalist rule is defined by $\widetilde{E}_{t}^{f} y_{t+1}=0$

\footnotetext{
${ }^{2}$ It is now standard in DSGE-models to use a pricing equation in which marginal costs enter on the right hand side. Such an equation is derived from profit maximisation in a world of imperfect competition. It can be shown that under certain conditions the aggregate supply equation (3) is equivalent to such a pricing equation (see Gali(2008), Smets and Wouters(2003)).
} 
The extrapolative rule is defined by $\widetilde{E}_{t}^{e} y_{t+1}=y_{t-1}$

This kind of simple heuristic has often been used in the behavioural finance literature where agents are assumed to use fundamentalist and chartist rules (see Brock and Hommes(1997), Branch and Evans(2006), De Grauwe and Grimaldi(2006)). It is probably the simplest possible assumption one can make about how agents, which experience cognitive limitations, use rules that embody limited knowledge to guide their behavior. In this sense they are bottom-up rules. They only require agents to use information they understand, and do not require them to understand the whole picture.

Thus the specification of the heuristics in (4) and (5) should not be interpreted as a realistic representation of how agents forecast. Rather is it a parsimonious representation of a world where agents do not know the "Truth" (i.e. the underlying model). The use of simple rules does not mean that the agents are dumb and that they do not want to learn from their errors. I will specify a learning mechanism later in this section in which these agents continuously try to correct for their errors by switching from one rule to the other.

The market forecast is obtained as a weighted average of these two forecasts, i.e.

$$
\begin{aligned}
& \widetilde{E}_{t} y_{t+1}=\alpha_{f, t} \widetilde{E}_{t}^{f} y_{t+1}+\alpha_{c, t} \widetilde{E}_{t}^{e} \\
& \widetilde{E}_{t} y_{t+1}=\alpha_{f, t} 0+\alpha_{c, t} y_{t-1} \\
& \text { and } \alpha_{f, t}+\alpha_{e, t}=1
\end{aligned}
$$

where $\alpha_{f, t}$ and $\alpha_{e, t}$ are the probabilities that agents use a fundamentalist, respectively, an extrapolative rule.

A methodological issue arises here. The forecasting rules (heuristics) introduced here are not derived at the micro level and then aggregated. Instead, they are imposed ex post, on the demand and supply equations. This has also been the approach in the learning literature pioneered by Evans and Honkapohja(2001). Ideally one would like to derive the heuristics from the micro-level in an environment in which agents experience cognitive problems. Our knowledge about how to model this behaviour at 
the micro level and how to aggregate it is too sketchy, however, and I have not tried to do $\mathrm{so}^{3}$.

As indicated earlier, agents are rational in the sense that they continuously evaluate their forecast performance. I apply notions of discrete choice theory (see Anderson, de Palma, and Thisse, (1992) and Brock \& Hommes(1997)) in specifying the procedure agents follow in this evaluation process. Discrete choice theory analyzes how agents decide between different alternatives. The theory takes the view that agents are boundedly rational, i.e. utility has a deterministic component and a random component. Agents compute the forecast performance of the different heuristics as follows:

$$
\begin{aligned}
& U_{f, t}=-\sum_{k=1}^{\infty} \omega_{k}\left[y_{t-k}-\widetilde{E}_{f, t-k-1} y_{t-k}\right]^{2} \\
& U_{e, t}=-\sum_{k=1}^{\infty} \omega_{k}\left[y_{t-k}-\widetilde{E}_{e, t-k-1} y_{t-k}\right]^{2}
\end{aligned}
$$

where $U_{f, t}$ and $U_{e, t}$ are the forecast performances (utilities) of the fundamentalists and extrapolators, respectively. These are defined as the mean squared forecasting errors (MSFEs) of the optimistic and pessimistic forecasting rules; $\omega_{k}$ are geometrically declining weights.

Applying discrete choice theory the probability that an agent will use the fundamentalist forecasting rule is given by the expression (Anderson, de Palma, and Thisse, (1992) and Brock-Hommes(1997)):

$$
\alpha_{f, t}=\frac{\exp \left(\gamma U_{f, t}\right)}{\exp \left(\gamma U_{f, t}\right)+\exp \left(\gamma U_{e, t}\right)}
$$

Similarly the probability that an agent will use the extrapolative forecasting rule is given by:

$$
\alpha_{e, t}=\frac{\exp \left(\gamma U_{e, t}\right)}{\exp \left(\gamma U_{f, t}\right)+\exp \left(\gamma U_{e, t}\right)}=1-\alpha_{f, t}
$$

Equation (12) says that as the past forecast performance of the fundamentalists improves relative to that of the extrapolators agents are more likely to select the fundamentalist rule about the output gap for their future forecasts. As a result the

\footnotetext{
${ }^{3}$ Psychologists and brains scientists struggle to understand how our brain processes information. There is as yet no generally accepted model we could use to model the micro-foundations of information processing. There are some attempts to provide micro-foundations of models with agents experiencing cognitive limitations, though. See e.g. Kirman, (1992), Delli Gatti, et al.(2005).
} 
probability that agents use the fundamentalist rule increases. Equation (13) has a similar interpretation. The parameter $\gamma$ measures the "intensity of choice". It parametrizes the extent to which the deterministic component of utility determines actual choice. When $\gamma=0$ utility is purely stochastic. In that case agents decide to be fundamentalist or extrapolator by tossing a coin and the probability to be fundamentalist (or extrapolator) is exactly 0.5 . When $\gamma=\infty$ utility is fully deterministic and the probability of using a fundamentalist rule is either 1 or 0 . The parameter $\gamma$ can also be interpreted as expressing a willingness to learn from past performance. When $\gamma=0$ this willingness is zero; it increases with the size of $\gamma$.

Note that this selection mechanism is the disciplining device introduced in this model on the kind of rules of behaviour that are acceptable. Only those rules that pass the fitness test remain in place. The others are weeded out. In contrast with the disciplining device implicit in rational expectations models which implies that agents have superior cognitive capacities, we do not have to make such an assumption here.

It should also be stressed that although individuals use simple rules in forecasting the future, this does not mean that they fail to learn. In fact the fitness criterion used should be interpreted as a learning mechanism based on "trial and error". When observing that the rule they use performs less well than the alternative rule, agents are willing to switch to the more performing rule. Put differently, agents avoid making systematic mistakes by constantly being willing to learn from past mistakes and to change their behavior. This also ensures that the market forecasts are unbiased.

The mechanism driving the selection of the rules introduces a self-organizing dynamics in the model. It is a dynamics that is beyond the capacity of any one individual in the model to understand. In this sense it is a bottom-up system. It contrasts with the mainstream macroeconomic models in which it is assumed that some or all agents can take a bird's eye view and understand the whole picture. These agents not only understand the whole picture but also use this whole picture to decide about their optimal behaviour. Thus there is a one-to-one correspondence between the total information embedded in the world and the individual brains.

\section{Introducing heuristics in forecasting inflation}


Agents also have to forecast inflation. A similar simple heuristics is used as in the case of output gap forecasting, with one rule that could be called a fundamentalist rule and the other an extrapolative rule. (See Brazier et al. (2006) for a similar setup). The fundamentalist rule is based on the announced inflation target, i.e. agents using this rule have confidence in the credibility of this rule and use it to forecast inflation. The extrapolative rule is used by agents who do not trust the announced inflation target. Instead they extrapolate inflation from the past into the future.

The fundamentalist rule will be called an "inflation targeting" rule. It consists in using the central bank's inflation target to forecast future inflation, i.e.

$$
\widetilde{E}_{t}^{t a r}=\pi^{*}
$$

where the inflation target $\pi^{*}$ is normalized to be equal to 0

The "extrapolators" are defined by $E_{t}^{e x t} \pi_{t+1}=\pi_{t-1}$

The market forecast is a weighted average of these two forecasts, i.e.

$$
\widetilde{E}_{t} \pi_{t+1}=\beta_{t a r, t} \widetilde{E}_{t}^{\text {tar }} \pi_{t+1}+\beta_{\text {ext }, t} \widetilde{E}_{t}^{\text {ext }} \pi_{t+1}
$$

or

$$
\begin{aligned}
& E_{t} \pi_{t+1}=\beta_{t a r, t} \pi^{*}+\beta_{\text {ext }, t} \pi_{t-1} \\
& \text { and } \beta_{\text {tar }, t}+\beta_{\text {ext }, t}=1
\end{aligned}
$$

The same selection mechanism is used as in the case of output forecasting to determine the probabilities of agents trusting the inflation target and those who do not trust it and revert to extrapolation of past inflation, i.e.

$$
\begin{aligned}
& \beta_{\text {tar }, t}=\frac{\exp \left(\gamma U_{t a r, t}\right)}{\exp \left(\gamma U_{t a r, t}\right)+\exp \left(\gamma U_{\text {ext }, t}\right)} \\
& \beta_{\text {ext }, t}=\frac{\exp \left(\gamma U_{\text {ext }, t}\right)}{\exp \left(\gamma U_{t a r, t}\right)+\exp \left(\gamma U_{\text {ext }, t}\right)}
\end{aligned}
$$

where $U_{t a r, t}$ and $U_{e x t, t}$ are the weighted averages of past squared forecast errors of using targeter and extrapolator rules, respectively. These are defined in the same way as in (10) and (11). 
This inflation forecasting heuristics can be interpreted as a procedure of agents to find out how credible the central bank's inflation targeting is. If this is very credible, using the announced inflation target will produce good forecasts and as a result, the probability that agents will rely on the inflation target will be high. If on the other hand the inflation target does not produce good forecasts (compared to a simple extrapolation rule) the probability that agents will use it will be small.

The solution of the model is found by first substituting (3) into (1) and rewriting in matrix notation. This yields:

$$
\left[\begin{array}{cc}
1 & -b_{2} \\
-a_{2} c_{1} & 1-a_{2} c_{2}
\end{array}\right]\left[\begin{array}{l}
\pi_{t} \\
y_{t}
\end{array}\right]=\left[\begin{array}{cc}
b_{1} & 0 \\
-a_{2} & a_{1}
\end{array}\right]\left[\begin{array}{c}
\widetilde{E}_{t} \pi_{t+1} \\
\widetilde{E}_{t} y_{t+1}
\end{array}\right]+\left[\begin{array}{cc}
1-b_{1} & 0 \\
0 & 1-a_{1}
\end{array}\right]\left[\begin{array}{c}
\pi_{t-1} \\
y_{t-1}
\end{array}\right]+\left[\begin{array}{c}
0 \\
a_{2} c_{3}
\end{array}\right] r_{t-1}+\left[\begin{array}{c}
\eta_{t} \\
a_{2} u_{t}+\varepsilon_{t}
\end{array}\right]
$$

or

$$
A Z_{t}=B \tilde{E}_{t} Z_{t}+C Z_{t-1}+b r_{t-1}+v_{t}
$$

where bold characters refer to matrices and vectors. The solution for $Z_{t}$ is given by

$$
Z_{t}=A^{-1}\left|B \tilde{E}_{t} Z_{t}+C Z_{t-1}+b r_{t-1}+v_{t}\right|
$$

The solution exists if the matrix $\boldsymbol{A}$ is non-singular, i.e. if $\left(1-a_{2} c_{2}\right) a_{2} b_{2} c_{1} \neq 0$. The system (15) describes the solution for $y_{t}$ and $\pi_{t}$ given the forecasts of $y_{t}$ and $\pi_{t}$. The latter have been specified in equations (4) to (13) and can be substituted into (15). Finally, the solution for $r_{t}$ is found by substituting $y_{t}$ and $\pi_{t}$ obtained from (15) into (3).

My research strategy consists in comparing the dynamics of this behavioural model with the same structural model (aggregate demand equation (1), aggregate supply equation (2) and Taylor rule equation (3)) under rational expectations which we interpret as a stylized DSGE-model.

The model consisting of equations (1) to (3) can be written in matrix notation as follows:

$$
\left[\begin{array}{ccc}
1 & -b_{2} & 0 \\
0 & 1 & -a_{2} \\
-c_{1} & -c_{2} & 1
\end{array}\right]\left[\begin{array}{l}
\pi_{t} \\
y_{t} \\
r_{t}
\end{array}\right]=\left[\begin{array}{ccc}
b_{1} & 0 & 0 \\
-a_{2} & a_{1} & 0 \\
0 & 0 & 0
\end{array}\right]\left[\begin{array}{c}
E_{t} \pi_{t+1} \\
E_{t} y_{t+1} \\
E_{t} r_{t+1}
\end{array}\right]+\left[\begin{array}{ccc}
1-b_{1} & 0 & 0 \\
0 & 1-a_{1} & 0 \\
0 & 0 & a_{3}
\end{array}\right]\left[\begin{array}{l}
\pi_{t-1} \\
y_{t-1} \\
r_{t-1}
\end{array}\right]+\left[\begin{array}{l}
\eta_{t} \\
\varepsilon_{t} \\
u_{t}
\end{array}\right]
$$




$$
\begin{aligned}
& \Omega Z_{t}=\Phi E_{t} Z_{t}+\Lambda Z_{t-1}+v_{t} \\
& Z_{t}=\Omega^{-1}\left[\Phi E_{t} Z_{t}+\Lambda Z_{t-1}+v_{t}\right]
\end{aligned}
$$

This model can be solved under rational expectations using the Binder-Pesaran(1996) procedure.

\subsection{Calibrating the model}

I proceed by calibrating the model. In appendix A the parameters used in the calibration exercise are presented. The model was calibrated in such a way that the time units can be considered to be months. A sensitivity analysis of the main results to changes in the some of the parameters of the model will be presented. The three shocks (demand shocks, supply shocks and interest rate shocks) are i.i.d. with standard deviations of $0.5 \%$.

\section{Animal spirits, learning and forgetfulness}

In this section simulations of the behavioural model in the time domain are presented and interpreted. The upper panel of Figure 1 shows the time pattern of output produced by the behavioural model. A strong cyclical movement in the output gap can be observed. The lower panel of Figure 1 shows a variable called "animal spirits" ${ }^{4}$ It represents the evolution of the fractions of the agents who extrapolate a positive output gap. Thus when the curve reaches +1 all agents are extrapolating a positive output gap; when the curve reaches 0 no agents are extrapolating a positive output gap. In fact in that case they all extrapolate a negative output gap. Thus the curve shows the degree of optimism and pessimism of agents who make forecasts of the output gap.

Combining the information of the two panels in figure 1 it can be seen that the model generates endogenous waves of optimism and pessimism. During some periods optimists (i.e. agents who extrapolate positive output gaps) dominate and this translates into above average output growth. These optimistic periods are followed by pessimistic ones when pessimists (i.e. agents who extrapolate negative output gaps) dominate and the growth rate of output is below average. These waves of optimism

\footnotetext{
${ }^{4}$ See Mario Nuti (2009)on the different interpretations of "Animal Spirits". The locus classicus is Keynes(1936). See also Farmer(2006) and the recent book of Akerlof and Shiller(2009).
} 
and pessimism are essentially unpredictable. Other realizations of the shocks produce different cycles with the same general characteristics.

These endogenously generated cycles in output are made possible by a self-fulfilling mechanism that can be described as follows. A series of random shocks creates the possibility that one of the two forecasting rules, say the extrapolating one, delivers a higher payoff, i.e. a lower mean squared forecast error (MSFE). This attracts agents that were using the fundamentalist rule. If the successful extrapolation happens to be a positive extrapolation, more agents will start extrapolating the positive output gap. The "contagion-effect" leads to an increasing use of the optimistic extrapolation of the output-gap, which in turn stimulates aggregate demand. Optimism is therefore selffulfilling. A boom is created. At some point, negative stochastic shocks and/or the reaction of the central bank through the Taylor rule make a dent in the MSFE of the optimistic forecasts. Fundamentalist forecasts may become attractive again, but it is equally possible that pessimistic extrapolation becomes attractive and therefore fashionable again. The economy turns around.

These waves of optimism and pessimism can be understood to be searching (learning) mechanisms of agents who do not fully understand the underlying model but are continuously searching for the truth. An essential characteristic of this searching mechanism is that it leads to systematic correlation in beliefs (e.g. optimistic extrapolations or pessimistic extrapolations). This systematic correlation is at the core of the booms and busts created in the model. Note, however, that when computed over a significantly large period of time the average error in the forecasting goes to zero. In this sense, the forecast bias tends to disappear asymptotically.

The results concerning the time path of inflation are shown in figure 2. First concentrate on the lower panel of figure 2. This shows the fraction of agents using the extrapolator heuristics, i.e. the agents who do not trust the inflation target of the central bank. One can identify two regimes. There is a regime in which the fraction of extrapolators fluctuates around 50\% which also implies that the fraction of forecasters using the inflation target as their guide (the "inflation targeters") is around 50\%. This is sufficient to maintain the rate of inflation within a narrow band of approximately + and $-1 \%$ around the central bank's inflation target. There is a second regime though which occurs when the extrapolators are dominant. During this regime the rate of inflation fluctuates significantly more. Thus the inflation targeting of the central bank 
is fragile. It can be undermined when forecasters decide that relying on past inflation movements produces better forecast performances than relying on the central bank's inflation target. This can occur quite unpredictably as a result of stochastic shocks in supply and/or demand. We will return to the question of how the central can reduce this loss of credibility.

Figure 1: Output gap in behavioural model
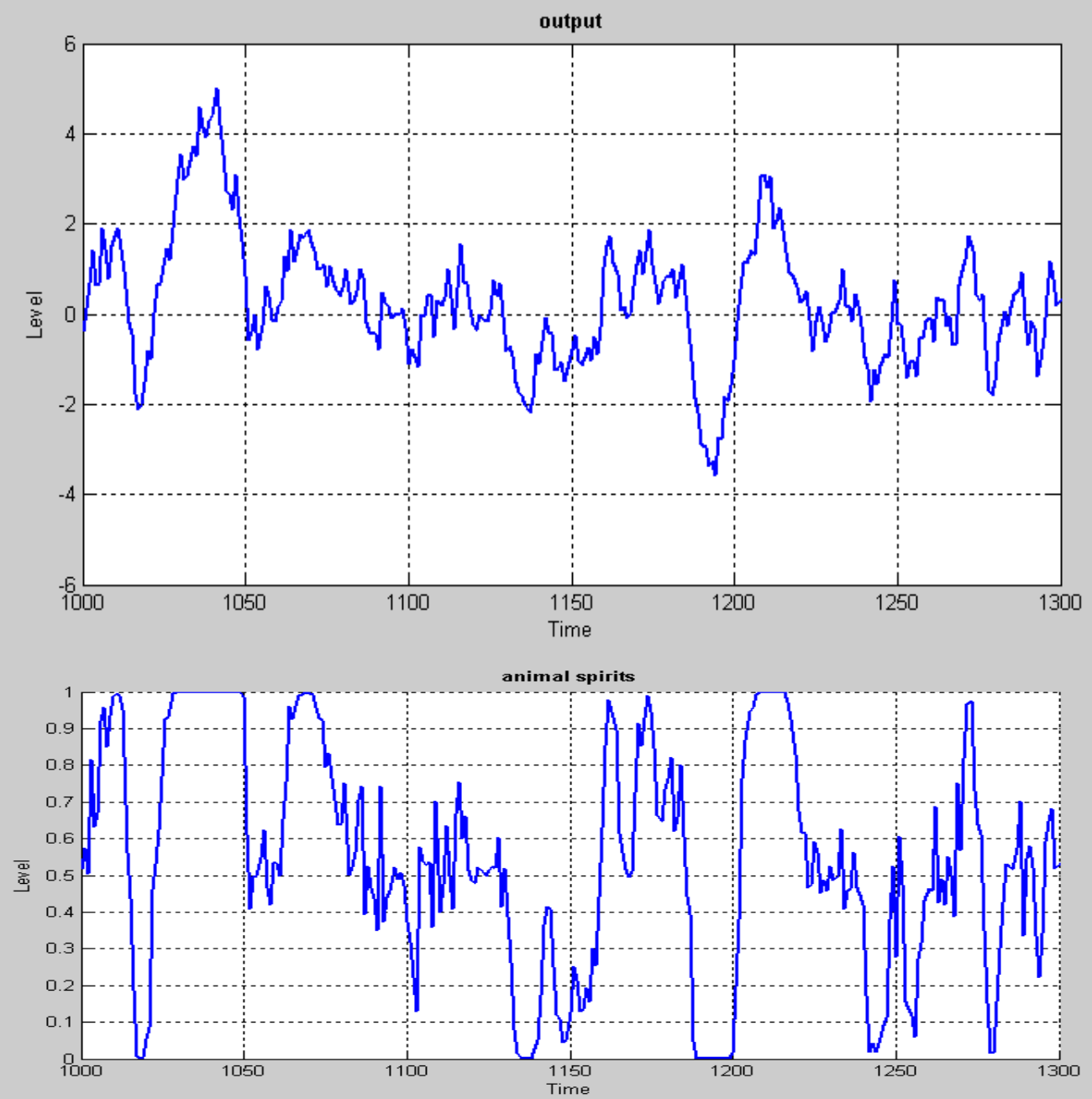
Figure 2 Inflation in behavioural model
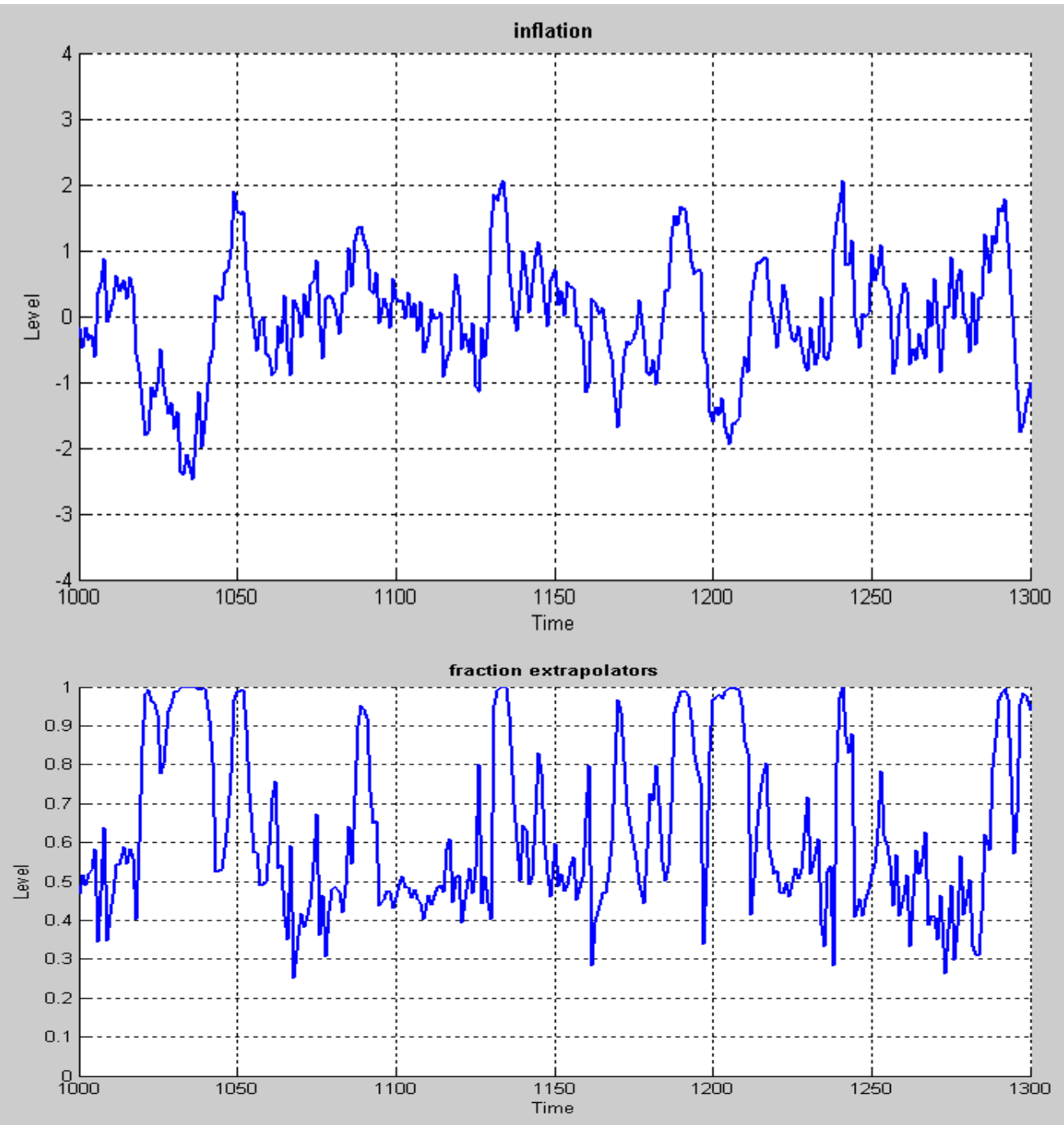

The simulations reported in the previous section assumed a given set of numerical values of the parameters of the model. It was found that for this set of parameter values animal spirits (measured by the movements in the fraction of optimistic extrapolators) emerge and affect the fluctuations of the output gap. The correlation coefficient between the fraction of optimists and the output gap in the simulation reported in figure 1 is 0.86 . One would like to know how this correlation evolves when one changes the parameter values of the model. I concentrate on two parameter values here, the intensity of choice parameter, $\gamma$, and the memory agents have when calculating the performance of their forecasting. The latter is represented by the parameter $\omega_{k}$ in equations (10)-(11) and is a series of declining weights attached to past forecast errors. I define $\omega_{k}=(1-\rho) \rho^{k}$ (and $\left.0 \leq \rho \leq 1\right)$. The parameter $\rho$ can 
then be interpreted as a measure of the memory of agents. When $\rho=0$ there is no memory; i.e. only last period's performance matters in evaluating a forecasting rule; when $\rho=1$ there is infinite memory, i.e. all past errors, however far in the past, obtain the same weight.

The results of the sensitivity analysis are shown in figure 3 . The left hand panel shows the correlation between the output gap and the fraction of optimistic extrapolators (animal spirits) for increasing values of the intensity of choice parameter, $\gamma$. It can be seen that when $\gamma$ is zero (i.e. the switching mechanism is purely stochastic), this correlation is zero. The interpretation is that in an environment in which agents decide purely randomly, i.e. they do not react to the performance of their forecasting rule, there are no systematic waves of optimism and pessimism (animal spirits) that can influence the business cycle. When $\gamma$ increases, the correlation increases sharply. Thus in an environment in which agents learn from their mistakes, animal spirits arise. Thus one needs a minimum level of rationality (in the sense of a willingness to learn) for animal spirits to emerge and to influence the business cycle. It appears from figure 3 that this is achieved with relatively low levels of $\gamma$.

The right hand panel shows the correlation between the output gap and the fraction of optimists for increasing values of the memory parameter $\rho$. It can be seen that when $\rho=1$ the correlation is zero. This is the case where agents attach the same weight to all past observations, however, far in the past they occur. Put differently, when agents have infinite memory; they forget nothing. In that case animal spirits do not occur. Thus one needs some forgetfulness (which is a cognitive limitation) to produce animal spirits. Note that the degree of forgetfulness does not have to be large. For values of $\rho$ below 0.98 the correlations between output and animal spirits are quite high.

Having presented the main features of the behavioural (bottom up) model I now proceed to show how this model leads to a view of macroeconomic dynamics that contrasts greatly with the view obtained from the rational expectations (top down) macroeconomic models . I concentrate on three areas. The first one has to do with the business cycle theories implicit in the behavioural and the rational expectations models. The second one focuses on the nature of the uncertainty in the two models and the third one on the implications for monetary policies. 
Figure 3 Correlations between output gap and fraction of optimists

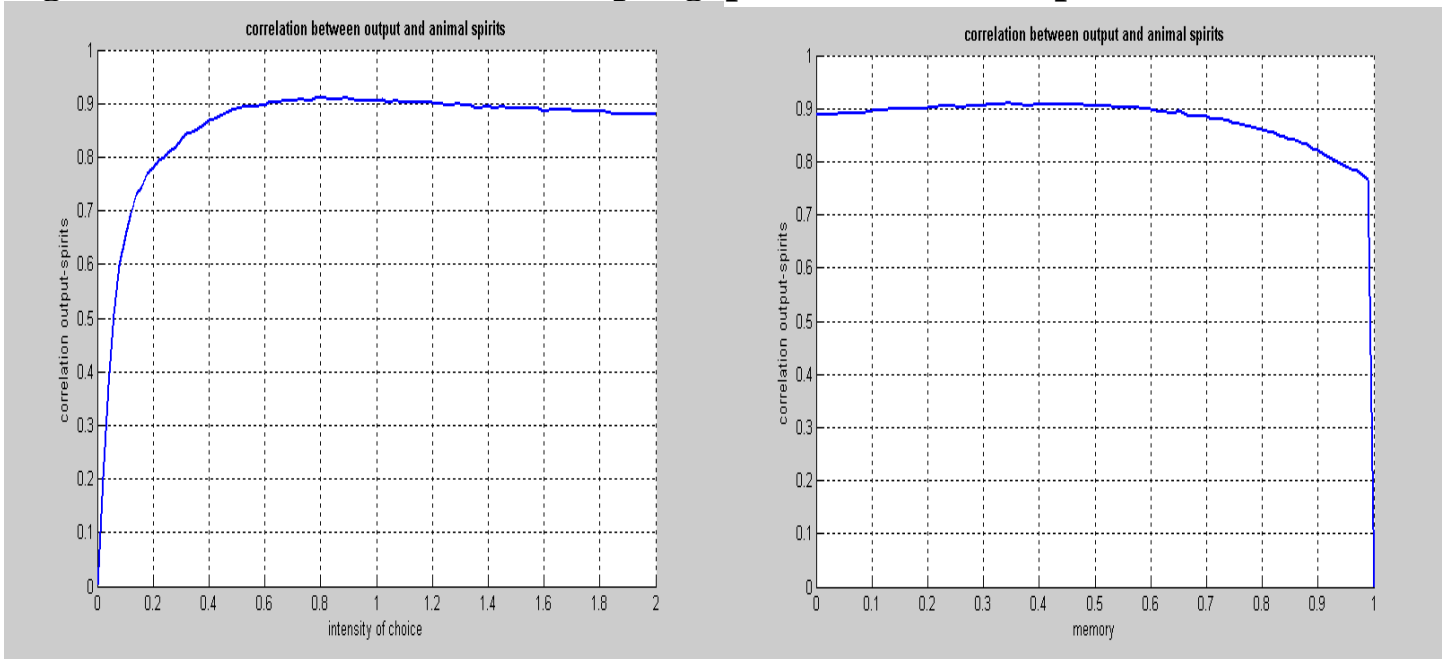

\section{Two different business cycle theories}

The behavioural and rational expectations macroeconomic models lead to very different views on the nature of business cycle. Business cycle movements in the rational expectations (DSGE) models arise as a result of exogenous shocks (in productivity and preferences) and lags in the transmission of these shocks to output and inflation. Thus inertia in output and inflation are the result of the lagged transmission of exogenous shocks. One could call the inertia (and the business cycles) introduced in the DSGE-model exogenously created phenomena ${ }^{5}$.

In contrast, the behavioural model presented here is capable of generating inertia (and business cycles) without imposing lags in the transmission process. This could be called endogenous inertia. This difference between the two models is illustrated by analyzing the behavioural and the rational models in the absence of lags in the transmission process in the demand and the supply equations. This is achieved by setting the parameters of the forward looking variables $a_{1}=1$ in equation (1) and $b_{1}=$ 1 in equation (2). The same i.i.d. shocks are then applied in both the behavioural and

\footnotetext{
${ }^{5}$ In a way it can be said that the lags in the transmission mechanism introduce an exogenous, some may say an ad-hoc, element into the logic of the DSGE-model. To give an example, Calvo pricing in which firms are constrained to adjust prices instantaneously (Christiano, Eichenbaum and Evans (2001)) is routinely imposed in DSGE models. It is clear, however, that such a restriction comes from outside the logic of the model. In a world where everybody understands the model and each other's rationality, which is at the core of the DSGE-models, agents would want to go immediately to the optimal plan using the optimal price. They would not want to accept such a restriction.
} 
the rational models and the autocorrelation coefficients of the simulated series of output gaps and inflation are computed. The results are shown in table 1. It can be seen that the behavioural model produces inertia (positive autocorrelation) in the output gap and in inflation even if there are no lags in the transmission of shocks. The rational model produces no inertia in the output gap and in inflation.

Table 1 also shows the autocorrelation coefficients obtained in models that assume lags in the transmission. These coefficients are obtained when $\mathrm{a}_{1}=0.5$ in equation (1) and $b_{1}=0.5$ in equation (2). These are also the numerical values assumed in all the simulations reported in the previous section. One now observes that inertia in the output gap and in inflation increases in both models. However, it can be concluded that all of the inertia obtained in the rational model is the result of the lags in the transmission process. This is not the case in the behavioural model where most of the inertia is produced endogenously.

Table 1 : Autocorrelation coefficients in output gap and inflation

No lags in transmission

\begin{tabular}{|c|c|c|}
\hline & behavioural model & rational model \\
\hline output gap & 0.77 & 0.07 \\
\hline inflation & 0.69 & -0.02 \\
\hline \multicolumn{3}{|c|}{ Lags in transmission } \\
\hline & behavioural model & rational model \\
\hline output gap & 0.89 & 0.79 \\
\hline inflation & 0.90 & 0.61 \\
\hline
\end{tabular}

Note: the autocorrelation coefficients are the averages obtained from simulating the model 1000 times, each time over 1000 periods.

It can also be seen from table 1 that even when the coefficients $a_{1}$ and $b_{1}$ of the forward looking variables of the model are set at 0.5 , the rational model produces less inertia than the behavioural model. The sensitivity of the autocorrelation coefficients to these parameters is explored more exhaustively in figure 4. This shows the autocorrelation coefficients as a function of $\mathrm{a}_{1}$ and $\mathrm{b}_{1}$. It can be observed that in the behavioural model the autocorrelation coefficients are not very sensitive to the $a_{1}$ and $b_{1}$. This contrasts a great deal with the results of the rational model, where the sensitivity is very high. When $a_{1}$ and $b_{1}$ are close to 1 (i.e. no or weak lags in the transmission process) the autocorrelation coefficients are very low (very low inertia). 
In order to produce inertia in the rational model which is of the same magnitude as in the behavioural model, $a_{1}$ and $b_{1}$ must be smaller than 0.5 .

This difference between the two models is quite fundamental. In the rational expectations model and in the absence of lags in the transmission, agents immediately find the optimal levels of output and inflation after some unanticipated shock. This results from their top-down position, i.e. they can instantaneously compute the effects this shock has on all the variables of the model making it possible to compute the optimal plan today and in the future. In order to produce the required inertia (and the business cycle movements), lags in the transmission preventing instantaneous adjustment to the optimal plan, are necessary.

The contrast with the behavioural model is great. Agents in this model do not fully understand how the shock will be transmitted. They have no top-down position. As a result they follow a procedure (heuristics together with a selection mechanism) that functions as a "trial and error" learning mechanism aimed at revealing the information about shocks and the transmission process. This is a slow bottom-up process that uses backward evaluation processes. It generates an endogenous inertia (and business cycle) into the model.

The inertia obtained in the behavioural model could also be called informational inertia. In contrast to the rational expectations model, agents in the behavioural model experience an informational problem. They do not fully understand the nature of the shock nor its transmission. They try to understand it by applying a trial and error learning rule, but they never succeed in fully understanding the complexity of the world. This cognitive problem then creates the inertia in output and prices. Thus one obtains very different theories of the business cycles in the two models ${ }^{6}$

\footnotetext{
${ }^{6}$ Critics of the heuristic model presented here may argue that the comparison between the rational and the behavioural model is unfair for the rational model. Indeed the heuristic model generates inertia because the evaluation and selection process of the different heuristics is backward looking. This is the reason why the behavioural model does not need lags in the transmission process to generate inertia. However, it can be argued that this evaluation and selection process can only be backward looking, and as a result, the lags that are present in the behavioural model are within the logic of that model. This contrasts with the lags introduced in the rational model: they come from outside the model. See Milani(2007b) who makes a similar point contrasting rational expectations models with learning models.
} 
Figure 4: Autocorrelation coefficients of output gap and inflation
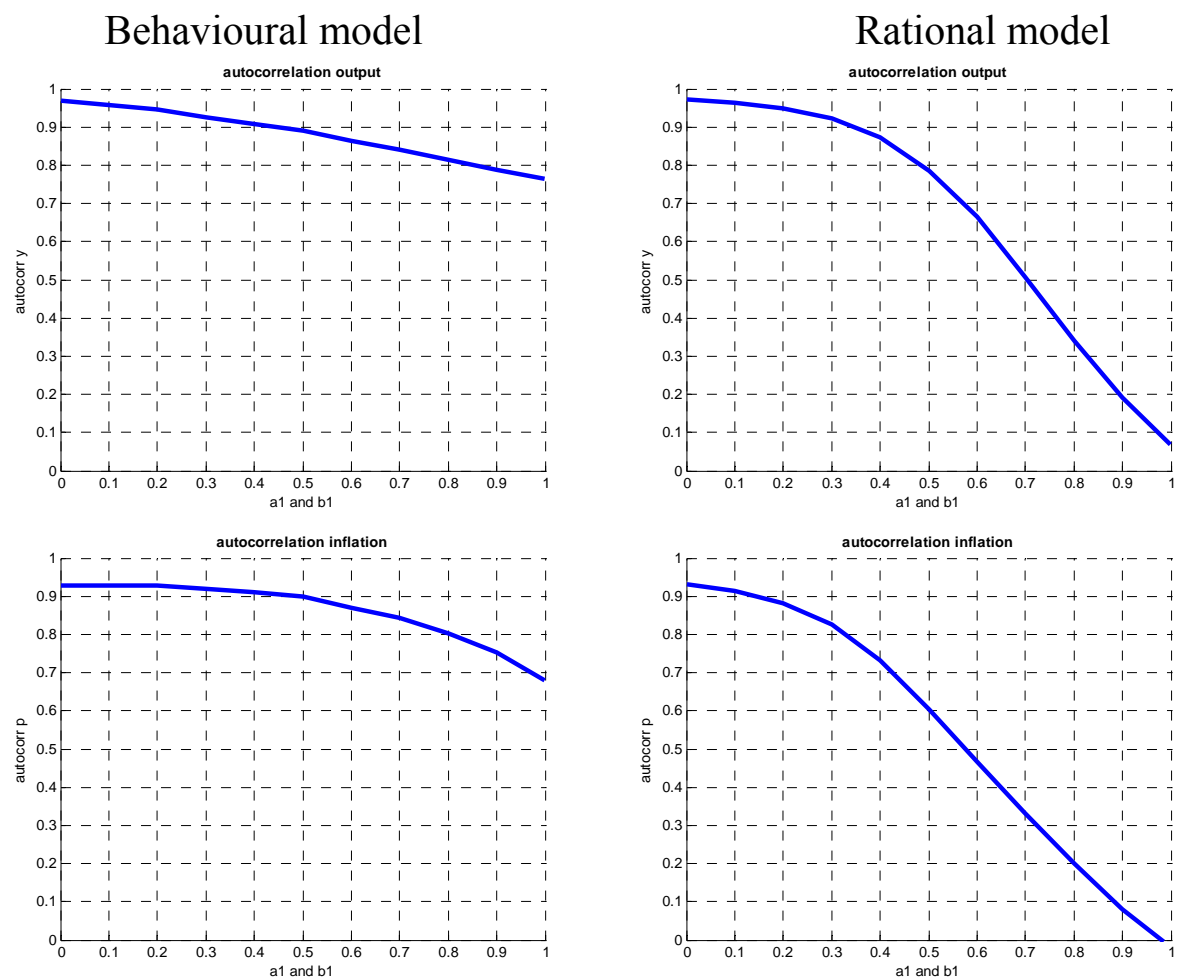

Note: see note of table 1 ; we have always set $a_{1}=b_{1}$

Mankiw and Reis(2002), (2006) have introduced a similar concept which they call "sticky information". There is a difference with the concept of informational inertia used in the present paper though. In Mankiw and Reis(2002) information inertia arises because agents do not immediately have access to the correct information. Once they obtain the information they set their plans optimally exactly as they would do in a rational expectations model without delays in the information flow. Thus in Mankiw and Reis(2002) the failure to understand is temporary. After a while rational expectations re-establishes itself.

The different natures of the business cycles in the DSGE-models and the behavioural model also have policy implications. In the DSGE-models now favoured by central banks, business cycle movements in output and prices originate from price and wage stickiness. In order to reduce this kind of volatility more flexibility in prices and wages is required. That is why many central banks call for more flexibility. In a more flexible world, central banks will not be called upon so often to stabilize output, and thereby set price stability at risk. 
In the behavioural model, business cycle movements in output arise from informational inertia. Thus, even if prices and wages become more flexible, this will not necessarily reduce the business cycle movements in output. As a result, society's desire to stabilize output will not be reduced. And central banks that inevitably respond to these desires will face the need to stabilize output at the risk of reducing price stability.

\section{The nature of uncertainty in the two models}

The behavioural and the rational expectations models produce a different view about the nature of uncertainty. We illustrate this feature by presenting impulse responses to shocks. Here I focus on the impulse responses to an interest rate shock, defined as plus one standard deviation of the shock in the Taylor equation.

The peculiarity of the behavioural model is that for the same parameters of the model the impulse responses are different for each realization of the stochastic shocks. This contrasts with the rational expectations model where the impulse response functions are not sensitive to the realization of the stochastic shocks (keeping the parameters unchanged).

Figure 5 shows the mean impulse responses to an interest rate shock. These were constructed by simulating the model 10,000 times with 10,000 different realizations of the shocks. The mean and median responses together with the standard deviations were then computed. Figure 5 shows the mean and median response (the dotted lines are + and -2 standard deviations from the mean response), exhibiting the standard result of an interest rate shock on output and inflation. However, the uncertainty surrounding this result is considerable at least in the short run. This contrasts with the rational expectations model which does not show such uncertainty (see figure 6). 
Figure 5: Mean impulse responses to interest rate shock in the behavioural model
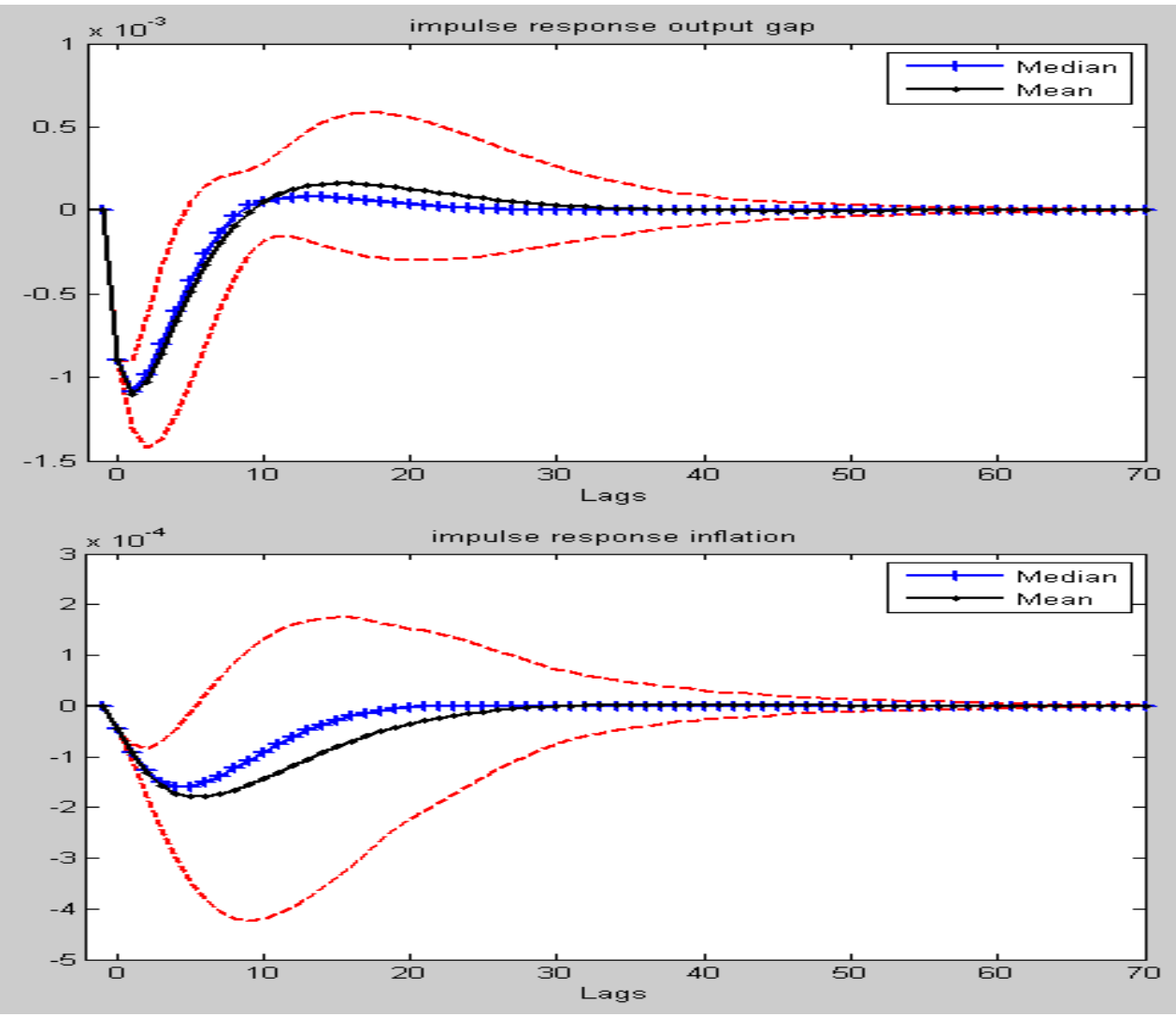

Note: The dotted lines represent the impulse responses with $+/-2$ standard deviations

Figure 6: Impulse responses to interest rate shock in rational model
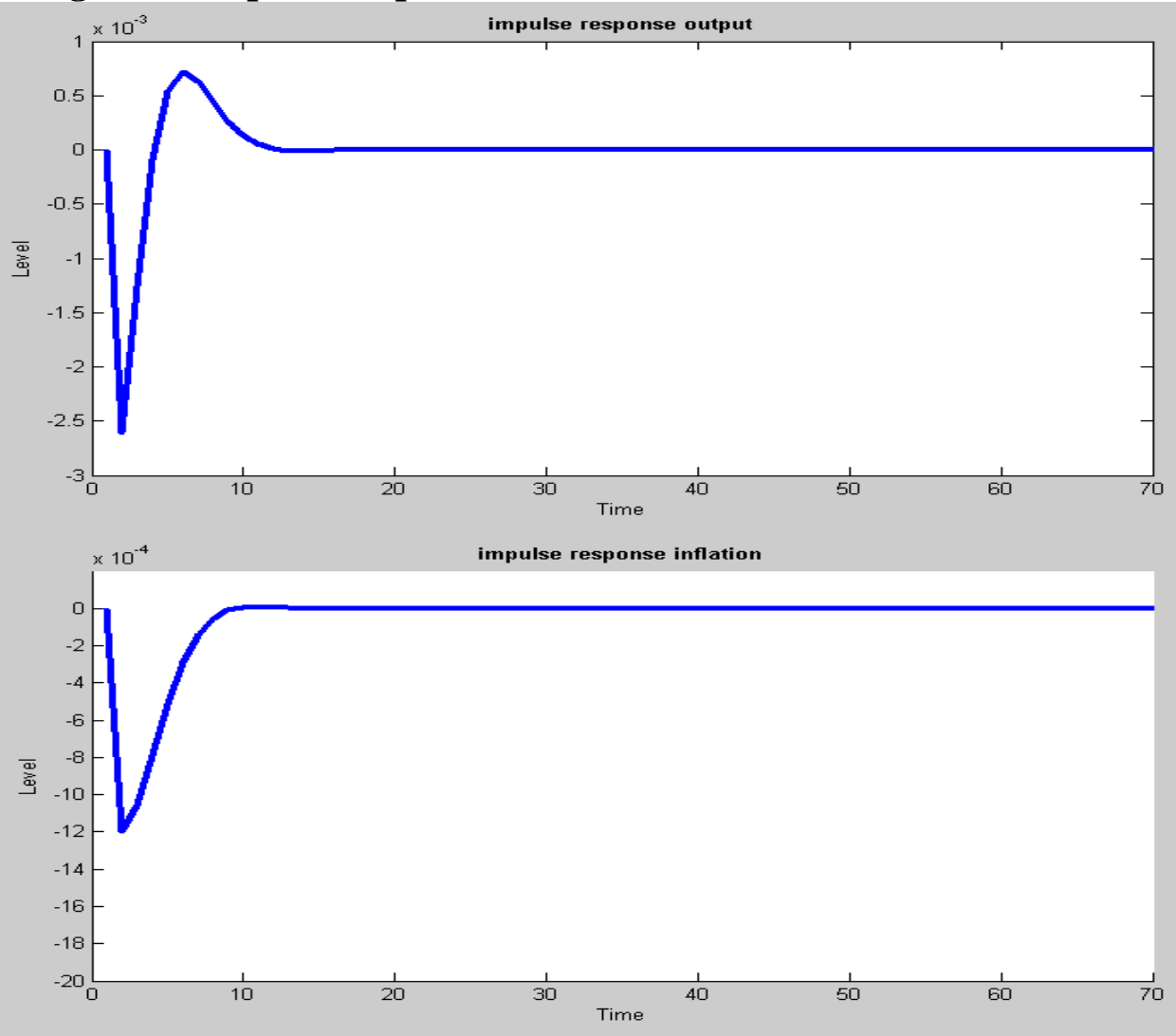
Where does this uncertainty come from? Not from parameter uncertainty. The same parameters are used in constructing all our impulse responses. The answer is that in this behavioural model each realization of the shocks creates different waves of optimism and pessimism (animal spirits). One could also call these "market sentiments". Thus a shock that occurs in one simulation happens in a different market sentiment than the same shock in another simulation. In addition, the shock itself affects market sentiments. As a result, the short-term effects of the same interest rate shock become very hard to predict.

Another way to interpret this result is to say that the timing of the shock is important. The same shocks applied at different times can have very different short-term effects on inflation and output. In other words, history matters. Note that the uncertainty about the impulse responses tends to disappear in the long run, as the effect of shortterm differences in market sentiments disappears ${ }^{7}$.

The previous discussion leads to the conclusion that the nature of the uncertainty in the two models is very different. In the top down structure of the rational expectations models, agents capable of overseeing the whole picture, compute with great precision how these shocks are transmitted. The question that arises here is whether the precision obtained in this model does not create an illusion among the practitioners of these models about what one can know in economics.

The contrast with the behavioural model is great. The bottom up structure of this model is one in which agents have only limited information. These agents with limited and heterogeneous information, follow rules of behaviour that when interacting with other rules lead to great complexity and a great amount of uncertainty about how an interest rate shock is transmitted. In fact our results suggest that even if

\footnotetext{
${ }^{7}$ This difference in the nature of uncertainty in a behavioural and a rational expectations model has everything to do with the fact that the former has non-linear features while the latter is linear. Thus the additional uncertainty produced by the behavioural model, i.e. the dependence of the impulse response functions on the state of the economy is the outcome of its non-linearity. Rational expectations models including the DSGE-models traditionally impose some linearization procedure. This is done for the sake of mathematical simplicity. It leads to a problem though. If the microfoundation of the model leads to a non-linear model, it is important to know how this non-linearity (which is part of the micro-foundation) affects the dynamics generated by the model. Eliminating these non-linearities amounts to destroying information that is relevant to predict the transmission of shocks. This may not matter much for the long run, but since the DSGE-models have the ambition of forecasting the transmission process, it is of significant importance.
} 
one knows the parameters of the model with certainty, it will not be possible to predict how a given shock in the interest rate applied at a particular time will be transmitted in the economy.

\section{The role of output stabilization}

Modern macroeconomics in general, and DSGE-models in particular, have provided the intellectual foundation of inflation targeting. Until the eruption of the financial crisis in 2007, inflation targeting strategies had become the undisputed policy framework modern central banks should adopt. And most did. The official holders of macroeconomic wisdom declared that this step towards inflation targeting constituted a great victory of macroeconomics as a science (Woodford(2009)). From now on we would be living in a more stable macroeconomic environment, a "Great Moderation". How things can change so quickly.

Inflation targeting, of course, does not imply that there is no role for output stabilization. DSGE-modelers who have put a New Keynesian flavor in their models, have always stressed that wage and price rigidities provide a rationale for output stabilization by central banks (see Clarida, et al(1999), Gali(2008)). This idea has found its reflection in "flexible" inflation targeting (Svensson(1997), Woodford(2002)). Because of the existence of rigidities, a central bank should not attempt to keep inflation close to its target all the time. When sufficiently large shocks occur that lead to departures of inflation from its target, the central bank should follow a strategy of gradual return of inflation to its target. The rationale is that in a world of wage and price rigidities too abrupt attempts to bring back inflation to its target would require such high increases in the interest rate as to produce too strong declines in output.

Output stabilization in the DSGE-world, however, is very much circumscribed. The need to stabilize arises because of the existence of rigidities in prices that makes it necessary to spread out price movements over longer periods. The limited scope for output stabilization is based on a model characterized by a stable equilibrium. There is no consideration of the possibility that the equilibrium may be unstable or that fluctuations in output have a different origin than price rigidities. Should the scope for output stabilization be enlarged? In order to shed some light on this issue we derive 
the tradeoff between output and inflation variability in the context of the behavioural model, and we formulate some policy conclusions.

The tradeoffs are constructed as follows. The model was simulated 10,000 times and the average output and inflation variabilities were computed for different values of the Taylor rule parameters. Figure 7 shows how output variability (panel a) and inflation variability (panel b) change as the output coefficient $\left(c_{2}\right)$ in the Taylor rule increases from 0 to 1 . Each line represents the outcome for different values of the inflation coefficient $\left(\mathrm{c}_{1}\right)$ in the Taylor rule.

Panel a showing the evolution of output variability exhibits the expected result, i.e. as the output coefficient $\left(\mathrm{c}_{2}\right)$ increases (inflation targeting becomes less strict) output variability tends to decrease. One would now expect that this decline in output variability resulting from more active stabilization comes at the cost of more inflation variability. This, however, is not found in panel b. One observes that the relationship is non-linear. As the output coefficient is increased from zero, inflation variability first declines. Only when the output coefficient increases beyond a certain value (in a range 0.6-0.8) inflation variability starts increasing. Thus the central bank can reduce both output and inflation variability when it moves away from strict inflation targeting $\left(c_{2}=0\right)$ and engages in some output stabilization. Not too much though. Too much output stabilization turns around the relationship and increases inflation variability.

Figure 7 allows us to construct the tradeoffs between output and inflation variability. These are shown in figure 8 for different values of the inflation parameter $c_{1}$. Take the tradeoff $\mathrm{AB}$. This is the one obtained for $\mathrm{c}_{1}=1$. Start from point $\mathrm{A}$ on the tradeoff. In point $\mathrm{A}$, the output parameter $\mathrm{c}_{2}=0$ (strict inflation targeting). As output stabilization increases we first move downwards. Thus increased output stabilization by the central bank reduces output and inflation variability. The relation is non-linear, however. At some point, with too high an output stabilization parameter, the tradeoff curve starts increasing, becoming a "normal" tradeoff, i.e. a lower output variability is obtained at the cost of increased inflation variability. 
Figure 7: Output and inflation variability

Panel a

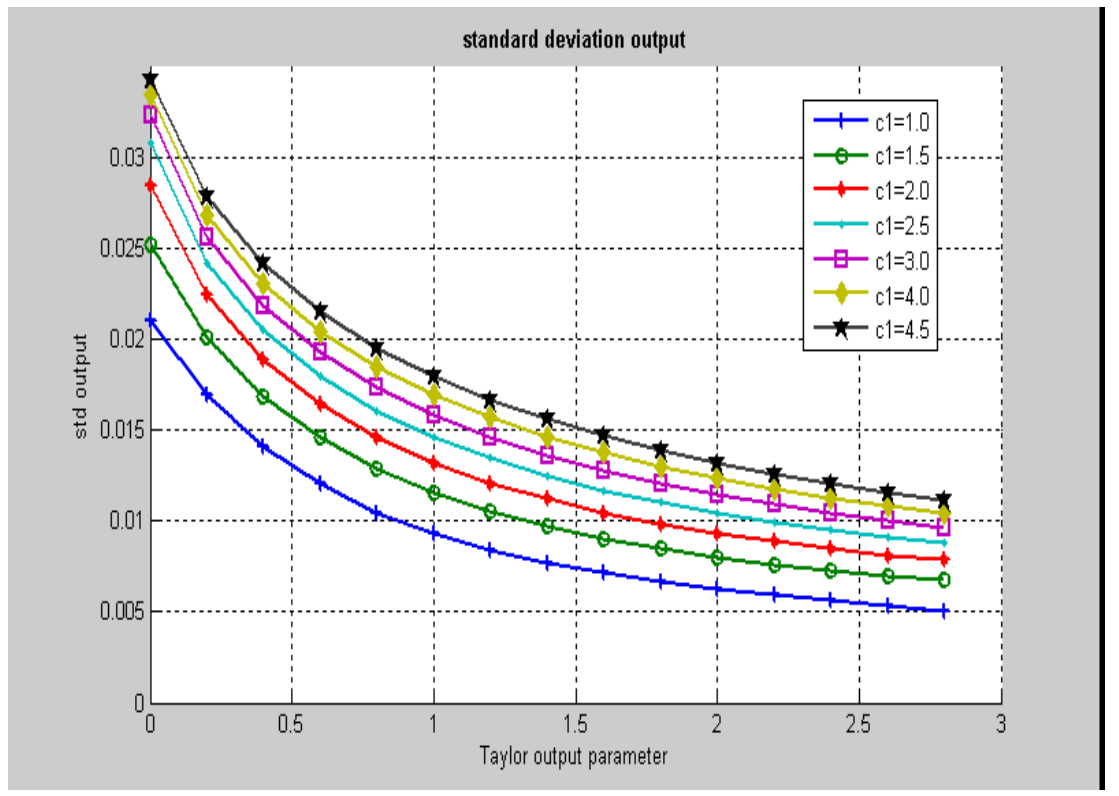

Panel b

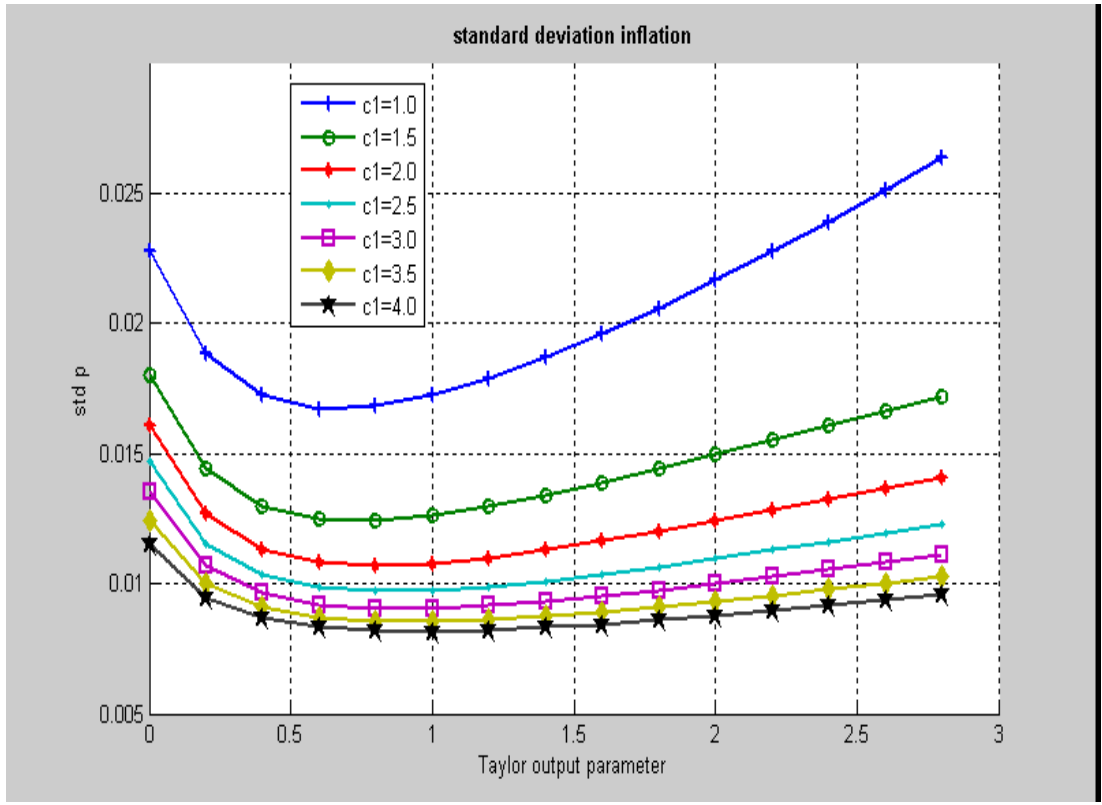


Figure 8: Trade-offs in the behavioural model

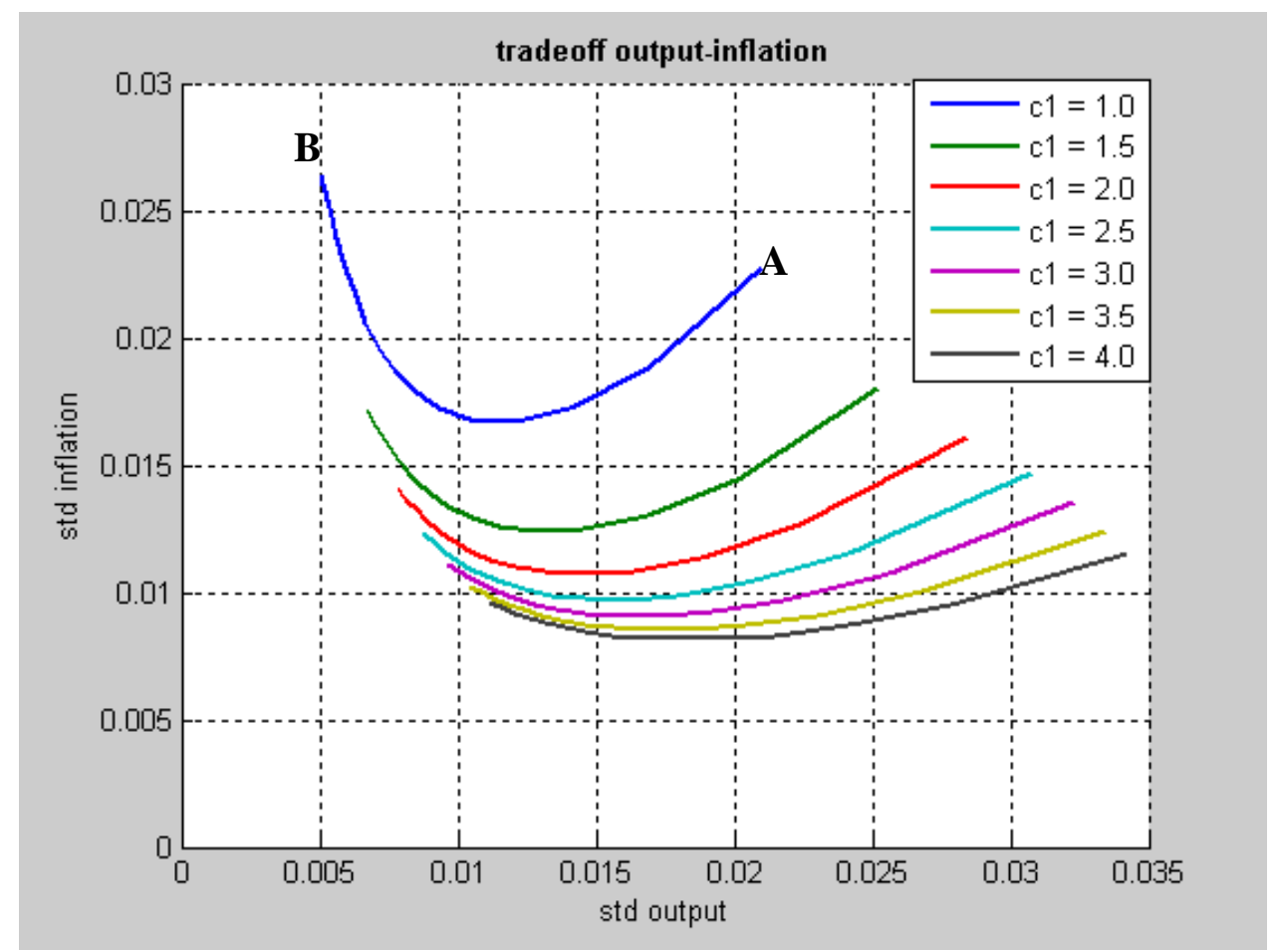

How can we interpret these results? Let us start from the case of strict inflation targeting, i.e. the authorities set $c_{2}=0$. There is no attempt at stabilizing output at all. The ensuing output variability intensifies the waves of optimism and pessimism (animal spirits) which in turn feed back on output volatility. These larges waves lead to higher inflation variability. Thus, some output stabilization is good; it reduces both output and inflation variability by preventing too large swings in animal spirits. With no output stabilization at all $\left(c_{2}=0\right)$ the forces of animal spirits are so high that the high output variability also increases inflation volatility through the effect of the output gap on inflation (supply equation). Too much output stabilization, however, reduces the stabilization bonus provided by a credible inflation target. When the central bank attaches too much importance to output stabilization it creates more scope for better forecasting performance of the inflation extrapolators, leading to more inflation variability.

Figure 8 also tells us something important about inflation targeting. We note that increasing the inflation parameter in the Taylor rule $\left(c_{1}\right)$ has the effect of shifting the tradeoffs downwards, i.e. the central bank can improve the tradeoffs by reacting more 
strongly to changes in inflation ${ }^{8}$. The central bank achieves this improvement in the tradeoff because by reacting more intensely to changes in inflation it reduces the probability that inflation extrapolators will tend to dominate the market, and as a result it reduces the probability that inflation targeting looses credibility. Such a loss of credibility destabilizes both inflation and output. Thus maintaining credibility of inflation targeting is an important source of macroeconomic stability in our behavioural model.

The previous results suggest that there is a relationship between the parameters $c_{1}$ and $\mathrm{c}_{2}$ in the Taylor equation and the credibility of the inflation target. This relationship can be analyzed in more detail. Inflation credibility can be given a precise definition in the model. It can be defined as the fraction of agents who use the inflation target to forecast inflation ("inflation targeters"). Thus when more agents use the announced inflation target to forecast inflation, credibility increases. Figure 9 presents the relationship between inflation credibility and the parameters $c_{1}$ and $c_{2}$. On the horizontal axis the parameter $\mathrm{c}_{2}$ (output parameter) is set out; on the vertical axis the inflation credibility. The latter is obtained by simulating the model 10,000 times and computing the mean fractions of inflation targeters for different values of the $\mathrm{c}_{1}$ and $c_{2}$. Each curve represents the relation between credibility and the output parameter $\left(c_{2}\right)$ for different values of the inflation parameter $\left(c_{1}\right)$. It has a non-linear feature, i.e. when the output parameter $c_{2}$ increases this has the effect of first increasing inflation credibility until a maximum is reached. Then credibility starts declining when $\mathrm{c}_{2}$ increases further. This non-linear feature is found for all values of $c_{1}$. Note that the maximum points obtained in figure 9 correspond to the minimum point of the tradeoffs in figure 8 .

These results have the following interpretation. When the central bank increases its effort to stabilize output this has at first a positive effect on the credibility of its inflation target. The reason, as was discussed earlier, is that by stabilizing output, the central bank also reduces the amplitude of the waves of optimism and pessimism thereby stabilizing output and inflation. Inflation credibility is maximized when $c_{2}$ is in a range between 0.5 and 1 . Beyond that range further attempts to stabilize output reduce inflation credibility for the reasons given earlier. The interesting aspect of this

\footnotetext{
${ }^{8} \mathrm{~A}$ similar result on the importance of strict inflation is also found in Gaspar, Smets and Vestin(2006) who use a macromodel with statistical learning.
} 
result is that the optimal values of $c_{2}$ are in a range often found in econometric studies of the Taylor equation. Thus central banks seem to apply a degree of output stabilization that is consistent with our theory of animal spirits.

Finally figure 9 shows that for increasing values of $\mathrm{c}_{1}$ the credibility curves increase. Thus a central bank can improve its inflation credibility by reacting more strongly to changes in inflation. This feature then underlies the result found in figure 8 that higher values of $\mathrm{c}_{1}$ improve the tradeoff between inflation and output variability.

Figure 9 Inflation credibility and output stabilization

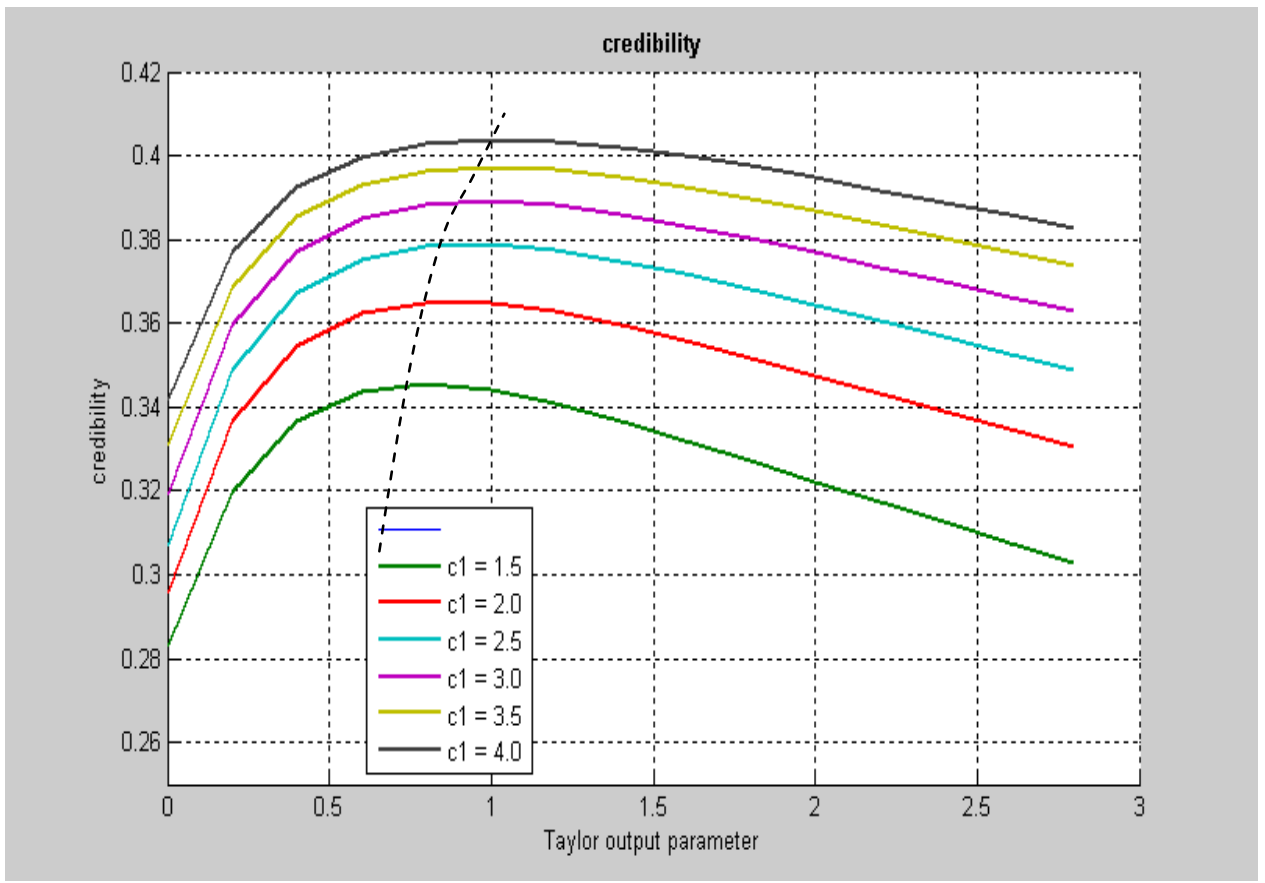

One can conclude that the behavioural model provides a different perspective about the need to stabilize output. This is a model that creates endogenous movements of the business cycle that are correlated with waves of optimism and pessimism. They are also unrelated to the existence of wage and price rigidities. These waves of optimism and pessimism both influence the output gap and in turn are also influenced by the output gap. We show this two-way causality feature in table 2 were the results of a Granger causality test on the output gap and the animal spirits (as defined in section 3) are presented. It can be seen that one cannot reject the hypotheses that animal spirits "Granger cause" the output gap and that the output gap "Granger causes" the animal spirits. 
This two-way causality between output gap and animal spirits creates the possibility for the central bank to reduce the waves of optimism and pessimism by reducing the volatility of output. In doing so, the central bank creates a more stable macroeconomic environment that also helps to stabilize inflation.

Table 2: Pairwise Granger Causality Tests

\begin{tabular}{lccc}
\hline \hline Null Hypothesis: & Obs & F-Statistic & Probability \\
\hline \hline Output does not Granger Cause optimism & 1948 & 31.0990 & $5.1 \mathrm{E}-14$ \\
Optimism does not Granger Cause output & & 32.8553 & $9.3 \mathrm{E}-15$ \\
& & & \\
\hline \hline
\end{tabular}

\section{An extension of the behavioural model}

The behavioural model discussed in the previous sections uses the assumption that the fundamentalist forecasters of the output gap know its steady state value. In this section we drop this assumption. Instead it will be assumed that because agents do not fully understand how the output gap is determined, their forecasts are biased. Some agents are optimistic and systematically bias the output gap upwards, others are pessimistic and systematically bias the output gap downwards.

The optimists are defined by $\widetilde{E}_{t}^{\text {opt }} y_{t+1}=g$

The pessimists are defined by $\widetilde{E}_{t}^{\text {pes }} y_{t+1}=-g$

where $g>0$ expresses the degree of bias in estimating the output gap.

The rule used by the extrapolators remains unchanged. For the sake of convenience it is repeated here, i.e.

$$
\widetilde{E}_{t}^{c} y_{t+1}=y_{t-1}
$$

The model now has three forecasting rules. As before a selection mechanism is assumed, whereby agents can switch between these three rules. This implies first that agents compute the performance (utility) of using these three rules. For the optimistic and pessimistic rules this becomes

$$
U_{o p t, t}=-\sum_{k=1}^{\infty} \omega_{k}\left[y_{t-k}-\widetilde{E}_{o p t, t-k-1} y_{t-k}\right]^{2}
$$




$$
U_{p e s, t}=-\sum_{k=1}^{\infty} \omega_{k}\left[y_{t-k}-\widetilde{E}_{p e s, t-k-1} y_{t-k}\right]^{2}
$$

The performance (utility) of the extrapolating rule was defined in equation (11) The corresponding probabilities of using the three rules now are:

$$
\begin{aligned}
& \alpha_{o p t, t}=\frac{\exp \left(\gamma U_{o p t, t}\right)}{\exp \left(\gamma U_{o p t, t}\right)+\exp \left(\gamma U_{p e s, t}\right)+\exp \left(\gamma U_{c, t}\right)} \\
& \alpha_{p e s, t}=\frac{\exp \left(\gamma U_{p e s, t}\right)}{\exp \left(\gamma U_{o p t, t}\right)+\exp \left(\gamma U_{p e s, t}\right)+\exp \left(\gamma U_{c, t}\right)} \\
& \alpha_{c, t}=\frac{\exp \left(\gamma U_{c, t}\right)}{\exp \left(\gamma U_{o p t, t}\right)+\exp \left(\gamma U_{p e s, t}\right)+\exp \left(\gamma U_{c, t}\right)}
\end{aligned}
$$

The model was simulated in the time domain using the same calibration as in the previous version of the model. The results are shown in figure 10. They are qualitatively the same as in the previous version, i.e. the model generates similar endogenous business cycles that are based on waves of optimism and pessimism. The other results of the model (not shown here) are also similar in nature, i.e. the uncertainty surrounding the impulse responses and the nature of the tradeoffs. 
Figure 10: Output gap and animal spirits in a three-agent model
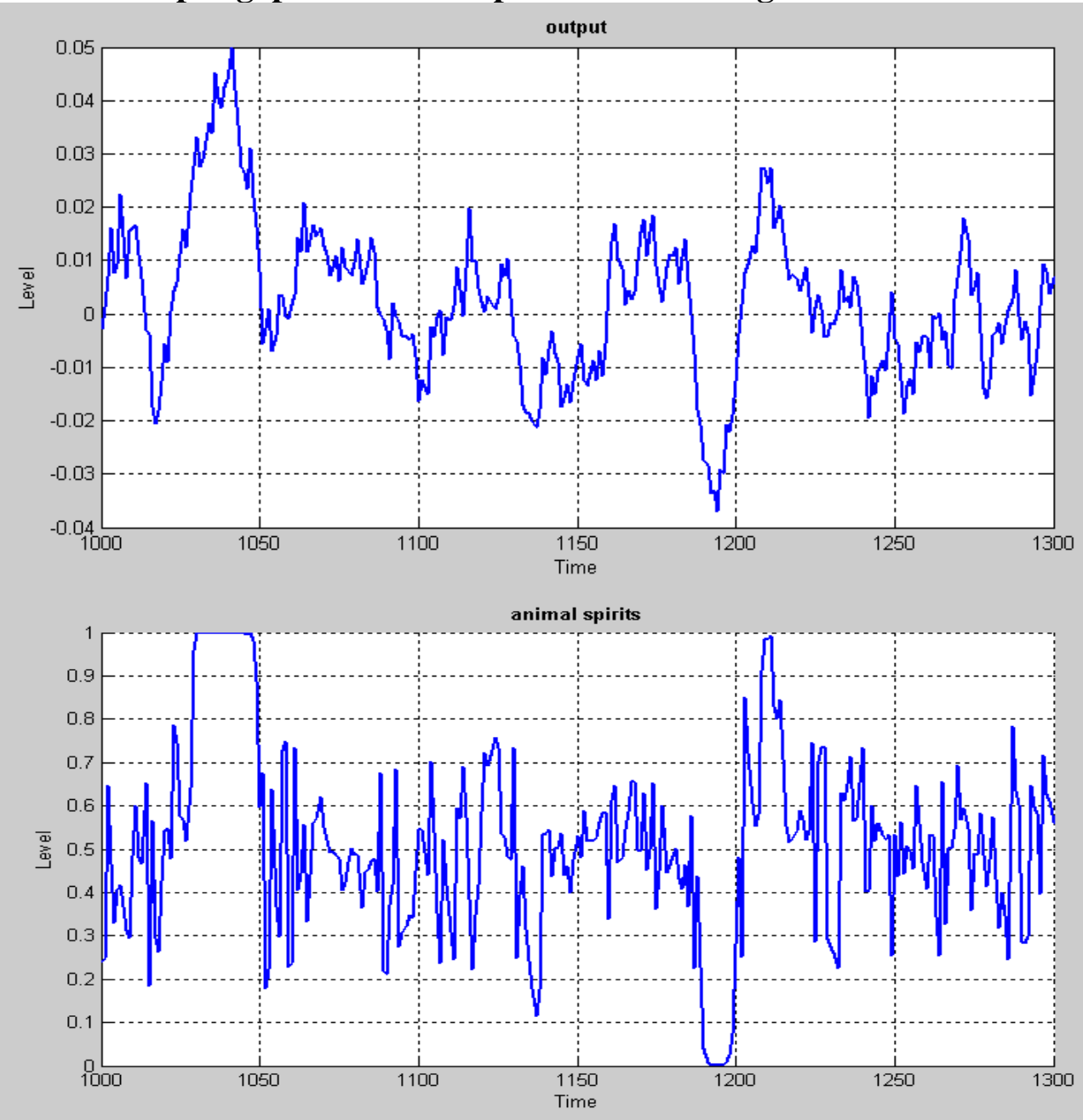

\section{Animal Spirits: theory and empirics}

The concept of animal spirits, i.e. waves of optimism and pessimism, has played a central role in the behavioural macroeconomic model presented in the previous sections. Is there an empirical counterpart for this concept? There is one, and it is widely used in day-to-day macroeconomic analysis. Many countries use survey based consumer and/or business sentiment indicators as a tool of analyzing the business cycle and as a predictive instrument.

The best-known sentiment indicator in the US is the Michigan Consumer Confidence indicator which has been in use since the 1950s. The first measures of consumer confidence were developed by George Katona in the late 1940s (see Katona(1951)). Since then similar indicators have been implemented in a large number of countries (see 
Curtin(2007) for an evaluation). Typically, sentiment indicators are constructed on the basis of a number of questions of how the individual perceives the present and the future economic conditions. Thus, these surveys produce two indices, one concerning present conditions, and one about future economic conditions. I will concentrate on the latter here, because this comes closest to the concept of optimism and pessimism used in this paper, which is forward looking. The structure of these questions usually presents the individual with a discrete choice between good-bad-neutral. An example from the Michigan indicator is the question: "Do you think that during the next twelve months, we'll have good times financially or bad times or what? [good times/uncertain/bad times]". The answers are then transformed into an index by computing the divergence between "good times" and "bad times" answers.

The question that is addressed in this section is to what extent these sentiment indicators behave in a way that is consistent with our behavioural macroeconomic model. In figure 11 the Michigan Consumer Confidence indicator is shown, together with the growth rate of US GDP (quarterly data) during 1980-2009. The correlated movements of the sentiment index and the growth rates of GDP are striking. The correlation coefficient was found to be 0.56 . Note that in the simulations reported in the previous sections the correlation coefficient between the output gap and the fraction of optimists was typically around 0.85 . The lower correlation observed in reality is related to the fact that the survey based sentiment indicators have a lot of noise. Also in figure 11 the consumer sentiment is compared to the growth of GDP, while in the theory sentiments and realizations relate to the same variable, output gap. In both cases, though, there is a similar pattern of contemporaneous correlation between sentiments and observed economic growth. 
Figure 11

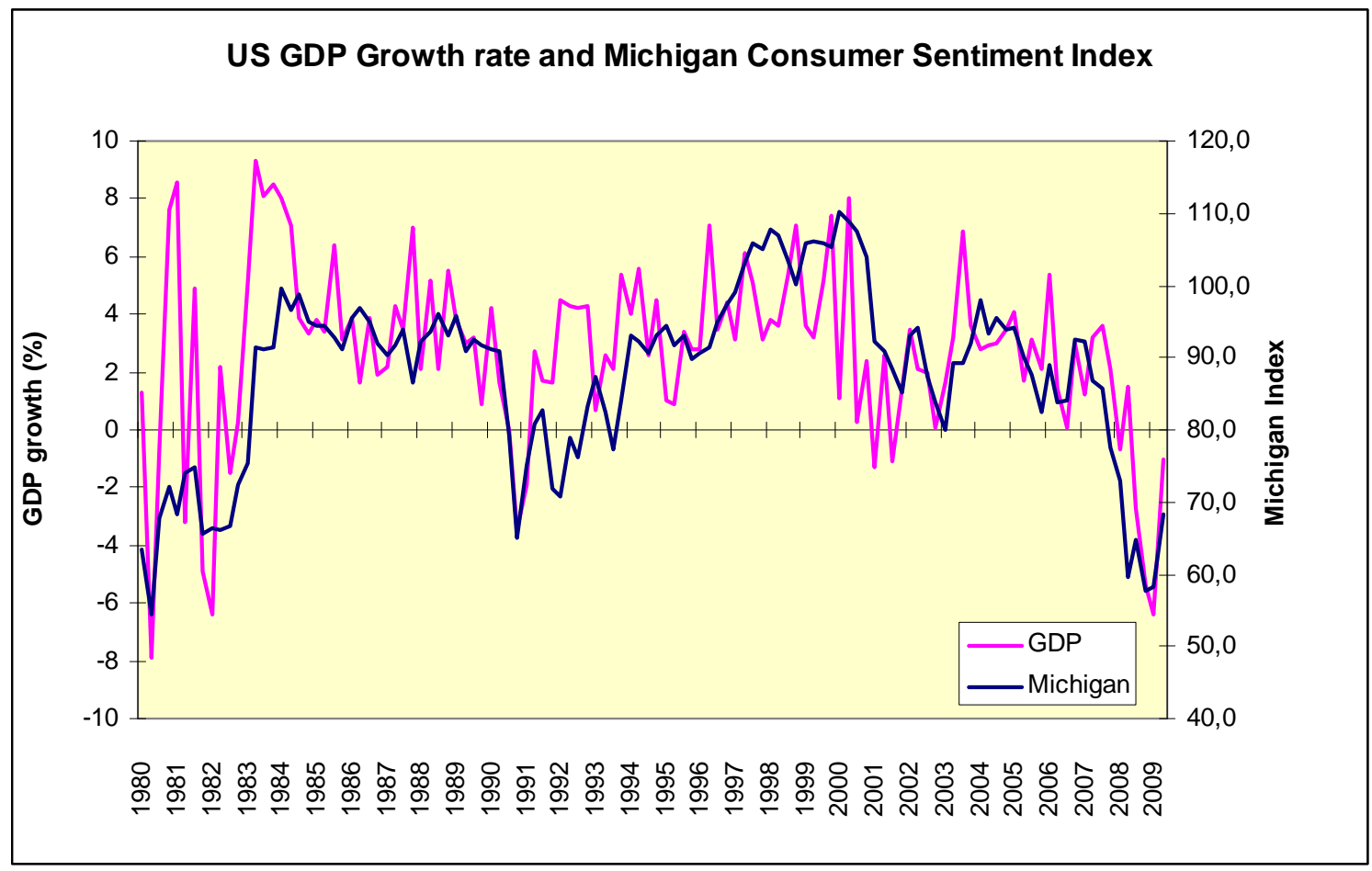

Source: US Department of Commerce, Bureau of Economic Analysis, and University of Michigan: Consumer Sentiment Index.

A typical feature of this correlation in the theoretical model is that the causality goes both ways, i.e. animal spirits affect output and output feeds back on animal spirits. We illustrated this by performing a Granger causality test on the simulated output gaps and the fractions of optimists (see table 2). It showed that one cannot reject the hypotheses that animal spirits Granger cause the output gap and that the output gap Granger causes the animal spirits. Can one find the same structure in the relation between the observed GDP growth rates and the Michigan Consumer Confidence indicator? The answer is provided in table 3. It shows that one cannot reject the hypothesis that the Michigan Consumer Confidence indicator Granger causes US GDP. The reverse is less clear-cut: there is some evidence that GDP Granger causes the Michigan Confidence indicator, but the level of significance is a borderline case. Curtin(2007) has shown that in a sample of more than 50 countries in a majority of these countries one finds two-way causality between the confidence indicator and GDP growth (or another proxy for the business cycle). 
Table 4: Pairwise Granger Causality Tests

\begin{tabular}{lccc}
\hline \hline Null Hypothesis: & Obs & F-Statistic & Probability \\
\hline \hline MICHIGAN does not Granger Cause GDP & 118 & 11.2085 & 0.001 \\
GDP does not Granger Cause MICHIGAN & & 2.33769 & 0.129 \\
\hline \hline
\end{tabular}

\section{Conclusion}

Macroeconomic models based on rational expectations assume extraordinary cognitive capabilities of individual agents. The latter are assumed to be capable of understanding the whole picture. This feature makes them top-down models. Recent developments in other disciplines including psychology and brain science document that individual agents struggle with limited cognitive abilities, restricting their capacity to understand the world. As a result, individual agents use small bits of information and simple rules to guide their behaviour.

I have used these new insights to develop a macroeconomic model in which the cognitive limitations of agents take center stage. I have called this a bottom-up model. Once one moves into a world of cognitive limitations one faces the problem that agents use simple and biased rules to forecast output and inflation. In order to provide discipline in the use of these rules a learning mechanism was introduced that allows for the selection of those rules that are more profitable than others. This learning mechanism ensures that although agents use biased rules the market forecasts are unbiased.

The ensuing behavioural model produces a number of results that distinguishes it from the rational expectations models. First, the behavioural model creates correlations in beliefs which in turn generate waves of optimism and pessimism. The latter produce endogenous cycles which are akin to the Keynesian animal spirits. These animal spirits are found to become more important when agents are willing to learn from the errors produced by biased beliefs. But, at the same time, there must be some forgetfulness about errors made long ago for animal spirits to emerge and to influence the business cycle. 
Second, the bottom-up behavioural model produces a degree of uncertainty about the transmission of monetary policy shocks that is different from the uncertainty obtained in rational expectations (DSGE) -models. In the latter linear models, uncertainty about the effects of monetary policy shocks arises only because of the lack of precision in the estimation of the structural parameters of the model. In the behavioural model there is an additional dimension to uncertainty. This is that the same policy shock can have different effects depending on the state of the economy, including the degree of optimism and pessimism agents have about the future. As a result, the transmission of policy shocks depends on the timing of these shocks. This is an insight not found in mainstream top-down models. In fact these models produce results whose precision is made possible because some agents are assumed to have unlimited cognitive abilities. Models with such features carry the risk of luring economists in believing that the transmission of shocks can be predicted with great confidence.

A third result is that the inflation targeting regime turns out to be of great importance to stabilize the economy in a behavioural model. The reason is that credible inflation targeting also helps to reduce correlations in beliefs and the ensuing self-fulfilling waves of optimism and pessimism. However, and this is where the behavioural model departs from the rational expectations model, strict inflation targeting is not an optimal policy. Some output stabilization (given a credible inflation target) also helps in reducing the correlation of biased beliefs thereby reducing the scope for waves of optimism and pessimism to emerge and to destabilize output and inflation.

Finally, the behavioural model provides for a very different theory of the business cycle as compared to the business cycle theory implicit in the rational expectations (DSGE) models. In the DSGE-models, business cycle movements in output and prices arise because rational agents cannot adjust their optimal plans instantaneously after an exogenous disturbance. Price and wage stickiness prevent such instantaneous adjustment. As a result, these exogenous shocks produce inertia and business cycle movements.

In contrast to the rational expectations model, agents in the behavioural model experience an informational problem. They do not fully understand the nature of the shock nor its transmission. They use a trial and error learning process aimed at distilling information. This cognitive problem then creates the inertia in output and prices. Thus a very different theory of the business cycles is obtained. 
These differences also have policy implications. In order to reduce output volatility in the DSGE-models more flexibility in prices and wages is required. That is why many central banks call for more flexibility of wages and prices. In a more flexible world, central banks will not be called upon so often to stabilize output, and thereby set price stability at risk.

In the behavioural model, business cycle movements in output arise from informational inertia. Thus, even if prices and wages become more flexible, this will not necessarily reduce the business cycle movements in output. As a result, society's desire to stabilize output will not be reduced. And central banks that inevitably respond to these desires will face the need to stabilize output.

The behavioural model proposed in this paper can be criticised for being "ad-hoc". There is no doubt that the model has ad-hoc features, i.e. assumptions that cannot be grounded on some deeper principle, and therefore have to be taken for granted. In defence of this "ad-hocquerie", the following should be stressed. Once we leave the comfortable world of agents who experience no limits to their cognitive abilities, adhoc assumptions are inevitable. This is due to the fact that we do not fully comprehend the way individuals with cognitive limitations process information. In contrast, there is no secret in how the superbly informed individuals in the rational expectations top down world process information. They understand the model, and therefore there is only one way to write down how they form their expectations. This feature may give the model builder intellectual satisfaction, but it is unclear whether such a model is useful to understand a world in which agents' cognitive capacities are severely restricted.

In addition, the current DSGE-models have attached many ad-hoc features aimed at improving the empirical fit which they fail to produce without these additions. All these ad-hoc additions (Calvo-pricing and other ad-hoc lags, rule of thumb consumers) constitute departures from rational behaviour. As a result, it is unclear how much of the dynamics of these models is produced by these ad-hoc additions rather than by the micro-founded rational behaviour.

The research presented in this paper should be considered to be preliminary. Although, some empirical evidence was provided suggesting that the behavioural macroeconomic model has some plausibility, a more rigorous empirical evaluation of 
the model will be necessary. In order to be convincing as an alternative modeling strategy, the predictions of the model will have to be confronted more systematically with the data. In addition, the menu of heuristics which is extremely small in this paper, will have to be broadened so that the selection of the "fittest" rules can occur using a wider pool of possible rules. 


\section{References:}

Adjemian, S., Darracq Pariès, M., Moyen, S., (2007), Optimal Monetary Policy in an Estimated DSGE-Model for the Euro Area, Working Paper, no. 803, European Central Bank.

Akerlof, G., and Shiller, R., (2009), Animal Spirits. How Human Psychology Drives the Economy and Why It Matters for Global Capitalism, Princeton University Press, 230pp.

Anagnostopoulos, A., Licandro, O., Bove, I., Schlag, K., (2007), An evolutionary theory of inflation inertia, Journal of the European Economic Association, 5, 433-443.

Anderson, S., de Palma, A., Thisse, J.-F., 1992, Discrete Choice Theory of Product Differentiation, MIT Press, Cambridge, Mass.

Anufriev, M;, Assenza, T., Hommes, C., Massaro, D., (2009), Interest Rate Rules and Macroeconomic Stability under Heterogeneous Expectations, CeNDEF, University of Amsterdam.

Binder, M., and M.H. Pesaran, (1996), Multivariate Rational Expectations Models and Macroeconomic Modeling: A Review and Some Results, in M.H. Pesaran and M. Wickens, eds., Handbook of Applied Econometrics: Macroeconomics.

Branch, W., and Evans, G., (2006), Intrinsic heterogeneity in expectation formation, Journal of Economic theory, 127, 264-95.

Brazier, A., Harrison, R., King, M., and Yates, T; (2006), The danger of inflating expectations of macroeconomic stability: heuristic switching in an overlapping generations monetary model, Working Paper no. 303, Bank of England, August.

Brock, W., and Hommes, C., 1997, A Rational Route to Randomness, Econometrica, $65,1059-1095$

Camerer, C., Loewenstein, G., Prelec, D., (2005), Neuroeconomics: How neurosciencecan inform economics, Journal of Economic Literature, 63(1), 964.

Chari, V., Kehoe, P., McGrattan, E., (2009), New Keynesian Models: Not Yet Useful for Policy Analysis, American Economic Journal: Macroeconomics, 1:1, p. 242-266.

Christiano, L., Eichenbaum, M., and Evans, C., (2001), Nominal Rigidities and the Dynamic Effects of a Shock to Monetary Policy, NBER Working Paper, no. 8403, July.

Christiano, L., Motto, R., Rostagno, M., (2007), Shocks, Structures or Monetary Policies, Working Paper, no. 774, European Central Bank.

Clarida, R., Gali, J., Gertler, M., (1999), The Science of Monetary Policy, A New Keynesian Perspective, Journal of Economic Literature, 37, 1661-1707.

Curtin, R., (2007), Consumer Sentiment Surveys: Worldwide Review and Assessment, Journal of Business Cycle Measurement and Analysis, 1-37 
De Grauwe, P., and Grimaldi, M., (2006), The Exchange Rate in a Behavioural Finance Framework, Princeton University Press.

Della Vigna, S., (2007, Psychology and Economics: Evidence from the Field, NBER Working Paper, no. 13420.

Delli Gatti, D., Di Guilmi, C;, Gaffeo, E., Giuloni, G., Gallegati, M., Palestrini, A., (2005), A new approach to business fluctuations: heterogenous interacting agents, scaling laws and financial fragility, Journal of Economic Behavior and Organization, vol. 56, 489-512

De Long, J., Bradford, B., Schleiffer and Summers, L., 1990, "Noise Trader Risk in Financial Markets", Journal of Political Economy.

Estrella, A., and Furher, J., Dynamic Inconsistencies: Counterfactual Implications of a Class of Rational Expectations Models, American Economic Review, 92(4), Sept., 1013-1028.

Evans, G., and Honkapohja, S., 2001, Learning and Expectations in Macroeconomics, Princeton University Press, 421pp.

Farmer, Roger, E.A., (2006), Animal Spirits, Palgrave Dictionary of Economics.

Galí, J., López-Salido, D., Vallés, J., (2004), Rule of Thumb Consumers and the Design of Interest Rate Rules, Journal of Money Credit and Banking, 36, no. 4, $739-764$.

Galí, J., (2008), Monetary Policy, Inflation and the Business Cycle, Princeton University Press, 203pp.

Gaspar, V., Smets, F., Vestin, D., (2006), Adaptive Learning, Persistence and Optimal Monetary Policy, Working Paper Series, no. 644, European Central Bank.

Gigerenzer, G., and P.M. Todd.1999. Simple Heuristics That Make Us Smart. New York: Oxford University Press.

Goodhart, C., (2007), The Continuing Muddles of Monetary Theory: A Steadfast Refusal to Face Facts,(mimeo), Financial Markets Group, London School of Economics

Hayek, F., (1945), The Use of Knowledge in Society, American Economic Review, XXXV, no. 4, 519-530.

Howitt, P., (2008), Macroeconomics with Intelligent Autonomous Agents, In Macroeconomics in the Small and the Large: Essays on Microfoundations, Macroeconomic Applications and Economic History in Honor of Axel Leijonhufvud, edited by Roger Farmer. Cheltenham: Edward Elgar..

Kahneman, D., and Tversky, A., 1973, Prospect Theory: An analysis of decisions under risk, Econometrica, 47, 313-327

Kahneman, D., and Tversky, A., 2000, Choices, Values and Frames, New York: Cambridge University Press.

Kahneman, D., 2002, Maps of Bounded Rationality: A Perspective on Intuitive Judgment and Choice, Nobel Prize Lecture, December 8, Stockholm

Kahneman, D., and Thaler, R., 2006, Utility Maximization and Experienced Utility, Journal of Economic Perspectives, 20, 221-234 
Katona, George. 1951. Psychological analysis of economic behavior. New York: McGraw-Hill

Keynes, J. M. (1936): The General Theory of Employment, Interest and Money. MacMillan and Co.

Kirman, A., (1993), Ants, Rationality and Recruitment, Quarterly Journal of Economics, 108: 137-156.

LeBaron,B., and Tesfatsion, L., (2008), "Modeling Macroeconomies as Open-Ended Dynamic Systems of Interacting Agents", American Economic Review (Papers \& Proceedings), Volume 98, No. 2, pp. 246-250

Leijonhufvud, A., (1993), Towards a Not-Too-Rational Macroeconomics, Southern Economic Journal, Vol. 1, no. 1, July.

Ludvigson, S., (2004), Consumer Confidence and Consumer Spending, Journal of Economic Perspectives, 18:2, Spring

Mankiw, N. Gregory and Ricardo Reis (2002). "Sticky Information versus Sticky Prices: A Proposal to Replace the New Keynesian Phillips Curve." Quarterly Journal of Economics, 117 (4), 1295-1328.

Mankiw, N. Gregory and Ricardo Reis (2006) "Pervasive Stickiness.” American Economic Review, 96 (2), 164-169..

Milani, F., (2007a), Learning and Time-Varying Macroeconomic Volatility, mimeo, University of California, Irvine.

Milani, F., (2007b), Expectations, Learning and Macroeconomic Persistence, Journal of Monetary Economics, 54, 2065-2082.

Nelson, E., (1998), Sluggish Inflation and Optimizing Models of the Business Cycle, Journal of Monetary Economics, 42(2), Oct., 303-322.

Orphanides, A., and Williams, J., (2004), Robust Monetary Policy with Imperfect Information, Board of Governors of the Federal Reserve System.

Sargent, T. 1993. Bounded Rationality in Macroeconomics. Oxford University Press.

Sims, C., (2005), Rational Inattention: A Research Agenda, Discussion Paper, no. 34/2005, Deutsche Bundesbank.

Smets, F. and Wouters, R., (2003), An Estimated Dynamic Stochastic General Equilibrium Model, Journal of the European Economic Association, 1, 11231175.

Smets, F., and Wouters, R., (2007), Shocks and Frictions in Us Business Cycles, Working Paper, no. 722, European Central Bank.

Stanovich, K., and West, R., 2000, Individual differences in reasoning: Implications for the rationality debate, Behavioural and Brain Sciences, 23, 645--665.

Svensson, L., (1997), Inflation Forecast Targeting: Implementing and Monitoring Inflation Targets, European Economic Review, 41: 111-46.

Tesfatsion, L; (2006), Agent-Based Computational Economics: A Constructive Approach to Economic Theory, pp. 831-880 in Leigh Tesfatsion and Kenneth L. Judd (eds.), Handbook of Computational Economics, Volume 2: Agent- 
Based Computational Economics, Handbooks in Economics Series, NorthHolland/Elsevier, the Netherlands, Spring 2006.

Thaler, R., 1994, Quasi Rational Economics, Russell Sage Foundation, New York.

Tversky, A., and Kahneman, D., 1981, The framing of decisions and the psychology of choice, Science, 211, 453-458.

Walsh, C., (2003), Monetary Theory and Policy, MIT-Press, 612 pp.

Woodford, M., (2003), Interest and Prices: Foundations of a Theory of Monetary Policy, Princeton University Press.

Woodford, M., (2009), Convergence in Macroeconomics: Elements of the New Synthesis, American Economic Journal: Macroeconomics, Vol. 1, no. 1, January, 267-97. 


\section{Appendix : parameter values of the calibrated model}

\section{Heuristic model}

pstar $=0$

a $1=0.5$

$\mathrm{a} 2=-0.2$

$\mathrm{b} 1=0.5$;

b2 $=0.05$;

$\mathrm{c} 1=1.5$

$\mathrm{c} 2=0.5$

$\mathrm{c} 3=0.5$;

$\beta=1$;

$\delta=2$;

gamma $=1$;

sigma $1=0.5$

sigma2 $=0.5$

sigma3 $=0.5$

rho $=0.5$;
$\%$ the central bank's inflation target

$\%$ coefficient of expected output in output equation

$\% \mathrm{a}$ is the interest elasticity of output demand

$\% \mathrm{~b} 1$ is coefficient of expected inflation in inflation equation

$\% \mathrm{~b} 2$ is coefficient of output in inflation equation

$\% \mathrm{c} 1$ is coefficient of inflation in Taylor equation

$\% \mathrm{c} 2$ is coefficient of output in Taylor equation

$\%$ interest smoothing parameter in Taylor equation

$\%$ fixed divergence in beliefs

$\%$ variable component in divergence of beliefs

$\%$ intensity of choice parameter

$\%$ standard deviation shocks output

$\%$ standard deviation shocks inflation

$\%$ standard deviation shocks Taylor

$\%$ rho measures the speed of declining weights in mean squares

errors (memory parameter)

\section{Rational model}

pstar $=0$;

al $=0.5$;

a2 $=-0.2$;

$\mathrm{b} 1=0.5$

b2 $=0.05$;

$\mathrm{c} 1=1.5$

$\mathrm{c} 2=0.5$

$\mathrm{c} 3=0.5$

sigma1 $=0.5$

sigma $2=0.5$

sigma $3=0.5$
$\%$ the central bank's inflation target

$\%$ coefficient of expected output in output equation

$\%$ a is the interest elasticity of output demand

$\% \mathrm{~b} 1$ is coefficient of expected inflation in inflation equation

$\% \mathrm{~b} 2$ is coefficient of output in inflation equation

$\% \mathrm{c} 1$ is coefficient of inflation in Taylor equation

$\% \mathrm{c} 2$ is coefficient of output in Taylor equation

$\%$ interest smoothing parameter in Taylor equation

$\%$ standard deviation shocks output

$\%$ standard deviation shocks inflation

\%standard deviation shocks Taylor 